\title{
FINDING OF NO SIGNIFICANT IMPACT \\ OPERATION OF THE HB-LINE FACILITY AND \\ FRAME WASTE RECOVERY PROCESS FOR \\ PRODUCTION OF Pu-238 OXIDE \\ AT THE SAVANNAH RIVER SITE
}

\section{AGENCY: Department of Energy}

ACTION: Finding of No Significant Impact

SUMMARY: The Department of Energy (DOE) has prepared an environmental assessment (EA), DOE/EA-0948, addressing future operations of the HB-Line facility and the Frame Waste Recovery process at the Savannah River Site (SRS), near Aiken, South Carolina. Based on the analyses in the EA, DOE has determined that the proposed action is not a major Federal action significantly affecting the quality of the human environment within the meaning of the National Environmental Policy Act (NEPA) of 1969. Therefore, DOE has concluded that the preparation of an environmental impact statement is not required, and is issuing this Finding of No Significant Impact.

\section{PUBLIC AVAILABILITY:}

Public meetings concerning the proposed future operation of HB-Line were held in North Augusta, South Carolina, and Savannah, Georgia, on January 18 and 20, 1994, respectively. The draft EA was forwarded to the States of South Carolina and Georgia and interested persons for comment in October 1994. Public meetings to discuss the proposed action and the draft EA were held in North Augusta, South Carolina, on December 6, 1994, and in Savannah, Georgia, on December 8, 1994.

Copies of the EA and FONSI and further information on the DOE NEPA process are available from:

A. B. Gould, Jr.

SR NEPA Compliance Officer

Savannah River Operations Office

U. S. Department of Energy

P. O. Box A

Aiken, South Carolina 29802

Voice mail or facsimile transmission: 1-800-242-8269 
BACKGROUND: The HB-Line facility and Frame Waste Recovery process are used to produce plutonium-238 ( $\mathrm{Pu}-238$ ) oxide for use as a heat source in radioisotope thermoelectric generators and light-weight radioisotope heater units for National Aeronautics and Space Administration missions. DOE is currently producing Pu-238 oxide in the HB-Line facility and the Frame Waste Recovery process for the National Aeronautics and Space Administration's Cassini mission. DOE has prepared an EA to assess the environmental impacts of operating the HB-Line facility and the Frame Waste Recovery process following completion of current operations. The EA was prepared as a result of a settlement of a lawsuit filed against DOE by the Energy Research Foundation of Columbia, South Carolina, on January 4, 1993. Current operations were assessed in an EA prepared in 1991; a Finding of No Significant Impact was issued in July 1991.

PROPOSED ACTION: The proposed action is for DOE to continue to operate and maintain the $\mathrm{Pu}-238$ processing facilities at the Savannah River Site and process the available inventory of $\mathrm{Pu}-238$ scrap material into a usable oxide powder to preserve the capability to support NASA missions. Processing of the five kilograms of $\mathrm{Pu}-238$ purchased from Russia and shipped to the SRS in 1994 is included in the proposed action. The proposed action also includes shipment of $\mathrm{Pu}-238$ scrap material ( $\mathrm{Pu}-238$ in forms and isotopic content that is not usable as heat source fuel without reprocessing) from DOE's Mound Laboratory, Miamisburg, Ohio, and the Los Alamos National Laboratory, Los Alamos, New Mexico, to the Savannah River Site.

ALTERNATIVES CONSIDERED: In addition to the proposed action, DOE considered the following alternatives:

(1) No Action. If this alternative were implemented, the $\mathrm{Pu}-238$ processing facilities would continue to operate until completion of the campaign for the Cassini Mission, currently estimated to be June, 1995. Once this mission had been fulfilled, operation of these facilities to support $\mathrm{Pu}-238$ processing would be terminated. This alternative does not allow for the processing of material to support future missions.

(2) Alternative Processing Facility. Implementation of this alternative would involve processing Pu-238 material in facilities other than HB-Line and the Frame Waste Recovery process. Except as discussed below, because no other such facilities currently exist construction of new facilities would be required. Because this would be very costly, and because process efficiency or safety of the technology incorporated in the HB-Line facilities would not be improved upon, this is not considered a reasonable alternative. 


\section{DISCLAIMER}

This report was prepared as an account of work sponsored by an agency of the United States Government. Neither the United States Government nor any agency thereof, nor any of their employees, make any warranty, express or implied, or assumes any legal liability or responsibility for the accuracy, completeness, or usefulness of any information, apparatus, product, or process disclosed, or represents that its use would not infringe privately owned rights. Reference herein to any specific commercial product, process, or service by trade name, trademark, manufacturer, or otherwise does not necessarily constitute or imply its endorsement, recommendation, or favoring by the United States Government or any agency thereof. The views and opinions of authors expressed herein do not necessarily state or reflect those of the United States Government or any agency thereof. 


\section{DISCLAIMER}

Portions of this document may be illegible in electronic image products. Images are produced from the best available original document. 
(3) Alternative Vault Storage Facility. This alternative would involve using an SRS vault other than the HB-Line vault for storage of Processed Pu-238. Other vault facilities would require extensive modification to accommodate storage of $\mathrm{Pu}-238$, while the HB-Line vault is currently fully capable of storing Pu-238. Therefore, DOE does not consider modification of other facilities to be a reasonable alternative.

(4) Processing at the National Laboratories. In the United States, only the SRS and the Los Alamos National Laboratory have any capability to process Pu-238. The Los Alamos National Laboratory (LANL) has proposed adding the capability to conduct small scale Pu238 processing for scrap recovery in the existing plutonium handling facility. A new Pu-238 processing capability at LANL would be limited to approximately 100 to 300 grams per month, compared to SRS's 2,000 to 4,000 grams per month capacity. This is not considered a reasonable alternative to completing the processing of the U.S. Pu-238 inventory at SRS using existing, operating facilities at the SRS.

(5) Purchase of Pu-238 from Foreign Nations. This alternative would involve purchasing $\mathrm{Pu}$ 238 from foreign nations rather than processing the U.S. inventory into specification oxide powder using SRS facilities. Discussions with France and Great Britain have concluded that kilogram quantities of $\mathrm{Pu}-238$ could be made available by these countries sometime after 1999, but only after significant investment in new facilities. The U.S. has a contract in place with Russia for the purchase of up to $40 \mathrm{~kg}$ of Pu-238 through 1997. Five $\mathrm{kg}$ of Pu-238 have been purchased from Russia and are currently stored at the SRS pending processing as part of this proposed action. The necessary approvals and funding have been received for a second purchase of approximately $4 \mathrm{~kg}$. The Pu-238 oxide powder in the second purchase should not require chemical processing in U.S. facilities prior to use in fuel pellet fabrication operations. Funding for additional purchases of $\mathrm{Pu}-238$ is not included in the planned DOE Budgets for fiscal years 1995 and 1996. This alternative is not considered viable if DOE is to be responsive to NASA requirements as they arrive in the near term.

(6) Alternative Packaging and Storage of Pu-238. This alternative would involve continued operation of the $\mathrm{Pu}-238$ processing facilities until completion of the campaign for the Cassini mission. Once this mission had been completed, these facilities would operate to stabilize Pu-238 scrap materials stored at the SRS to meet the long-term storage criteria for plutonium. This alternative would require use of a new facility (the Actinide Packaging Facility) being considered for other purposes at the SRS. The stabilized, packaged Pu-238 
would be placed in an SRS vault. This alternative would ensure that material remaining at SRS would meet the long-term storage criteria, but is not considered viable is DOE is to be responsive to NASA requirements.

ENVIRONMENTAL IMPACTS: The potential consequences of the proposed action and alternatives were considered in the environmental assessment to determine whether there would be significant impacts due to the proposed action and the alternatives to ecological and cultural resources, the socioeconomic conditions in communities surrounding the SRS, and air, water, and the health and safety of the public and SRS workers.

No impacts to ecological or cultural resources, or to the socioeconomic conditions in communities surrounding the SRS, are expected as a result of the proposed action. The HB-Line is an existing facility that has been operating in several stages since 1985 . Because no modernization, construction, or additional employees would be required to implement the proposed action, the only socioeconomic impact would be from the continued employment of operational and maintenance personnel required to run the facility. Because no socioeconomic impacts would result from the proposed action, no differential impacts on minority or low income communities would result. The HB-Line facility was constructed in 1985 and is within a previously developed and highly industrialized area. Therefore, no endangered species, wetlands, cultural resources or other environmentally sensitive resources would be directly or indirectly impacted by the proposed action.

Normal Pu-238 processing would result in air and surface water emissions. Principal nonradiological air emissions would be carbon monoxide, nitrogen oxides, di-nitrogen oxide, nitric acid, and hydrogen fluoride. Emissions would be within air quality limits. Pu-238 processing operations would result in radiological emissions that would result in a dose of 0.005 millirem per year to the maximally exposed offsite individual. Radiological emissions to surface water as a result of $\mathrm{H}$-Area operations, including $\mathrm{Pu}-238$ processing, would result in a dose to the maximally exposed offsite individual of 0.0017 millirem per year to the maximally exposed offsite individual. Liquid effluent emissions are permitted by the South Carolina Department of Health and Environmental Control under the National Pollutant Discharge Elimination System. Air and water emissions resulting from normal operation of Pu-238 processing facilities are not expected to result in any adverse effects to the environment or human health and safety.

SRS worker exposures to radiation under normal operations would be controlled by established procedures that require doses be kept As Low As Reasonably Achievable (ALARA) and limit 
any individual's dose to 1.5 rem per year. Based on operations in 1993 and a maximum of 200 workers, DOE expects the average annual dose for $\mathrm{Pu}-238$ processing facility radiation workers from the proposed action would be less than 0.5 rem (or 500 millirem) per year. The cumulative worker dose would not exceed 100 person-rem per year. Based on an occupational risk factor of $4 \times 10^{-4}$ fatal cancers per person-rem, workers engaged in the operation of $\mathrm{Pu}-238$ processing facilities would not be expected to incur any health effects from radiation exposure.

Three types of waste would be generated from $\mathrm{Pu}-238$ processing operations: low-level radioactive waste, transuranic waste (including mixed transuranic waste), and radioactive liquid waste. Liquid waste would be transferred from the Frame Waste Recovery Process to the highlevel waste tanks where it would be stored until it can be converted to borosilicate glass and saltstone. Waste generated as a result of the proposed action would be a small fraction of the waste being managed at the SRS and would require no new waste management facilities or processes.

The consequences of facility accidents are evaluated in the environmental assessment. The highest consequence accident, a severe earthquake, could result in two latent cancer fatalities in the onsite population and five latent cancer fatalities in the offsite population. The probability of this accident occurring is calculated as $1.7 \times 10^{-4}$ per year. Impacts of other accidents are less severe. There is no credible transportation accident that would result in the release of radioactive material.

DETERMINATION: Based on the information and analyses in the EA, DOE has determined that the proposed future operation of HB-Line and the Frame Waste Recovery process at SRS does not constitute a major Federal action significantly affecting the quality of the human environment within the meaning of NEPA. Therefore, an environmental impact statement is not required.

Issued at Aiken, South Carolina, this

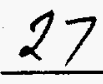
day of April, 1995.

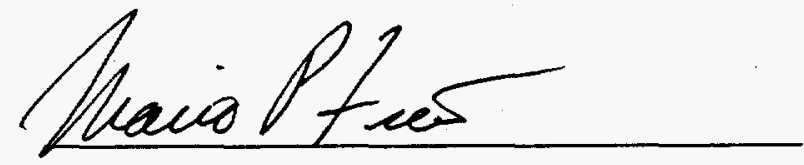

Mario P. Fiori, Manager

Savannah River Operations Office 
DOE/EA-0948

\section{ENVIRONMENTAL ASSESSMENT}

\section{OPERATION OF THE HB-LINE FACILITY AND}

FRAME WASTE RECOVERY PROCESS FOR PRODUCTION OF PU-238 OXIDE AT THE SAVANNAH RIVER SITE

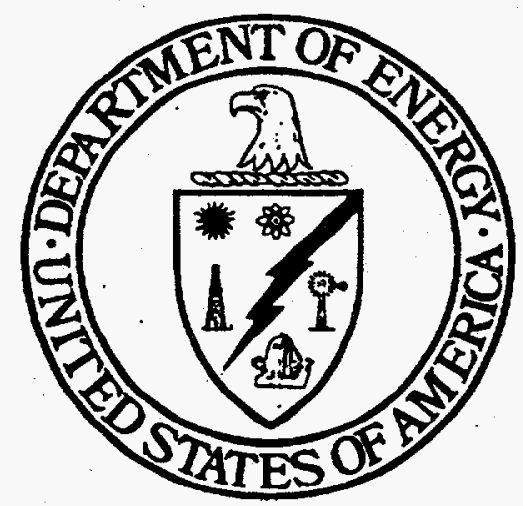

APRIL 1995

\section{UNITED STATES DEPARTMENT OF ENERGY SAVANNAH RIVER OPERATIONS OFFICE SAVANNAH RIVER SITE}




\section{TABLE OF CONTENTS}

1.0 PURPOSE AND NEED

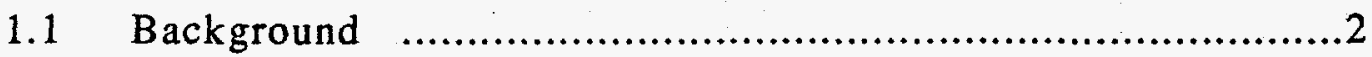

1.1.1 Power Systems for NASA Missions …….......................... 2

1.1.2 Pu-238 from Weapons Returns .................................... 4

1.1.3 Recent HB-Line Operations ….........................................4

2.0 PROPOSED ACTION AND ALTERNATIVES ................................... 6

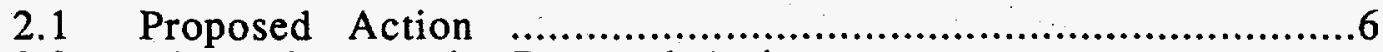

2.2 Alternatives to the Proposed Action …......................................

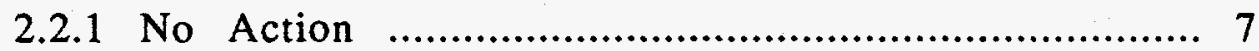

2.2.2 Alternative Processing Facility ........................................

2.2.3 Alternative Vault Storage Facility .........................................

2.2.4 Processing at the National Laboratories ..................................7

2.2.5 Purchase of $\mathrm{Pu}-238$ from Foreign Nations ..............................7

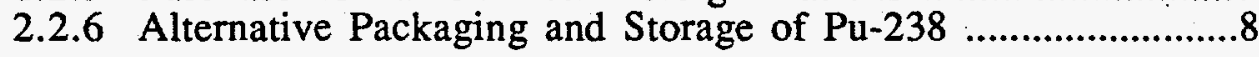

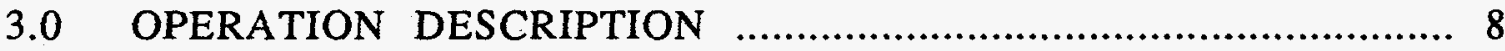

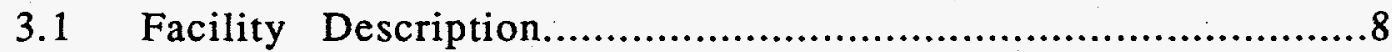

3.1.1 HB-Line Facilities..............................................

3.1.2 Frame Waste Recovery Process ...................................... 10

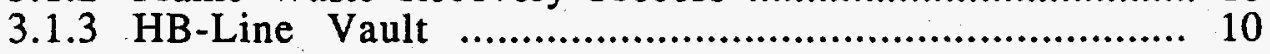

3.2 Processing Description ..................................................10

3.2.1 Scrap Recovery Facility (HB-Line Phase I) ............................10

3.2.2 Frame Waste Recovery (FWR) Unit...................................11

3.2.3 Plutonium Oxide Facility (HB-Line Phase III)....................... 11

3.3 Management \& Operation.................................................... 11

3.4 Description of Transportation Activities ........................................ 11

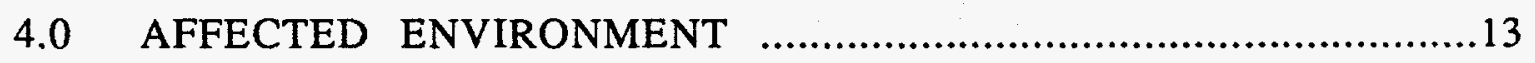

4.1 Geography, Demography, and Socioeconomics............................ 13

4.2 Radiation Environment ....................................................13

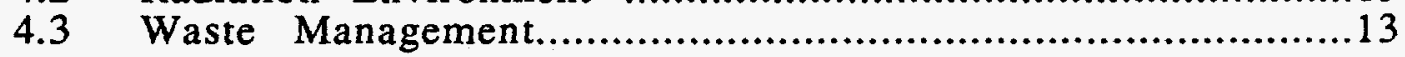

5.0 ENVIRONMENTAL CONSEQUENCES OF THE PROPOSED ACTION....... 14

5.1 Normal Facility Operations...................................................14

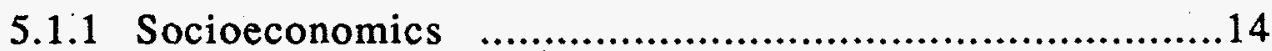

5.1.2 Ecology and Cultural Resources .......................................14

5.1.3 Air Emissions....................................................14

5.1.4 Surface Water Effluents ................................................17

5.1 .5 Worker Health Effects ................................................. 17 
5.1.6 Waste Management ............................................18

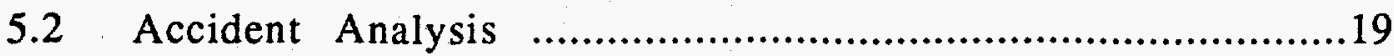

5.2.1 HB-Line Facilities (Phases I and III) .................................. 21

5.2.2 Frame Waste Recovery (FWR) .................................... 24

5.2.3 Onsite (SRS) Transportation Accidents ................................25

5.2.4 Incident-Free Off-site Transportation ................................. 26

5.2.5 Transportation Accidents ……..................................... 27

5.2.6 Nonradiological Transportation Accidents ………..................27

5.2.7 Health Effects …................................................. 28

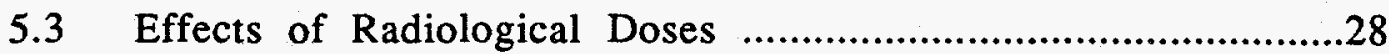

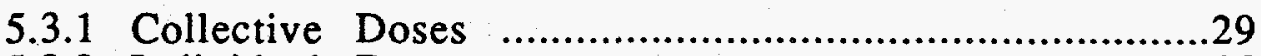

5.3.2 Individual Doses................................................ 29

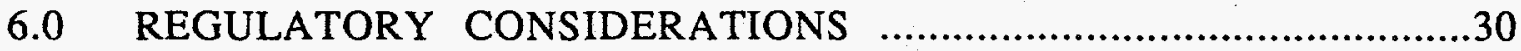

6.1 National Environmental Policy Act of 1969 .................................30

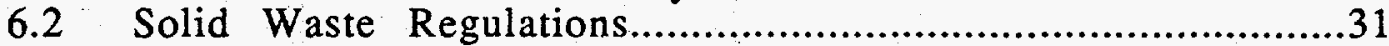

6.3 Air Emissions Regulations ................................................. 31

6.4 Liquid Discharge Regulations ...............................................31

6.5 Transportation Regulations ..................................................

7.0 PERSONS AND AGENCIES CONSULTED.................................... 31

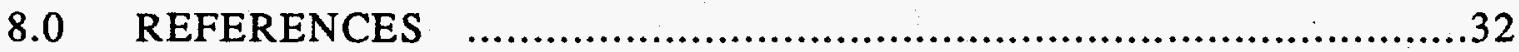

APPENDIXES:

APPENDIX A: Comments Recieved on the Draft EA, and DO Responses

\section{LIST OF FIGURES}

Page

Figure 3-1. H-Canyon Building and HB-Line Facilities ................................... 9

Figure 3-2. Pu-238 Material Flow Diagram................................................... 9

Figure 3-3. Pu-238 Process Flow Diagram.............................................. 12

Figure 4-1. Operational Areas at SRS....................................................... 15 


\section{LIST OF TABLES}

Page

Table 1-1 Estimated Pu-238 Fuel Requirements............................................. 3

Table 5-1 Non-Radiological Air Pollutants for Processing Pu-238 ....................... 16

Table 5-2 Atmospheric Radiological Emissions................................................ 16

Table 5-3 Liquid Radiological Effluents..................................................... 17

Table 5-4 HB-Line and FWR Waste Generation............................................ 19

Table 5-5 Facility Worker Qualitative Hazard Evaluation.....................................22

Table 5-6 Maximum Accident Dose Summary Scrap Recovery Facility.....................23

Table 5-7 Maximum Accident Dose Summary Plutonium Oxide Facility...................23

Table 5-8 Maximum Accident Dose to Populations............................................ 24

Table 5-9 Facility Worker Qualitative Hazard Evaluation......................................24

Table 5-10 Maximum Accident Dose Summary Frame Waste Recovery.....................25

Table 5-11 Maximum Accident Dose to Populations Frame Waste Recovery................25

Table 5-12 Onsite Transportation Accident Summary ........................................ 26

Table 5-13 Incident-Free Transportation Impacts for Shipments to SRS.................... 27

Table 5-14 Number and Probability of Latent Cancer Fatalities

for Incident-Free Transportation to SRS....................................................... 29

Table 5-15 Predicted Number of Latent Cancer Fatalities........................................30 


\subsection{PURPOSE AND NEED}

The National Aeronautics and Space Administration (NASA) is planning several space missions for the future that require a special plutonium-238 (Pu-238) oxide heat source fuel due to the duration and environmental conditions of the missions. This Environmental Assessment (EA) examines the impacts of operation of the HB-Line Facility and the Frame Waste Recovery (FWR) Process at the Savannah River Site (SRS) to process Pu-238 in support of these national program goals in space science applications. The EA evaluates alternatives to the proposed operation, including a new processing facility, alternate vault storage facility, processing at the National laboratories, purchase of Pu-238 from foreign nations, processing the inventory of Pu-238 Stored at SRS for long term storage, and not operating the HB-Line facility following completion of processing to support NASA's Cassini mission (no action).

The purpose of this agency action is to preserve DOE's capability to provide $\mathrm{Pu}-238$ oxide heat source fuel with the required chemical and isotopic specifications in support of national program goals in space science applications. No other radioisotope is available, qualified, or economically and technically practical to fulfill the unique requirements imposed by long term and independent operation in a space environment.

DOE prepares a budget each year for congressional approval which projects all programs and activities for the next five years. DOE prepares this budget by requesting its customers to project all work anticipated to occur within the next five years. Although Congress may approve the five year budget, they review and approve each year's annual budget in more detail the year prior to which the activities are scheduled to occur (e.g. the actual FY 1997 budget will be reviewed and approved in FY 1996). Lately, Congress has been drastically reducing the budgets of many Federal agencies within the year prior to the activity taking place.

NASA, one of DOE's customers, must also prepare its budget in the same manner. They prepare a list of projected missions and request funding to support these missions. DOE has an agreement with NASA to provide Pu-238 fueled power systems for space missions when these systems are required by mission objectives. In order to provide the $\mathrm{Pu}-238$ for some of the NASA missions, DOE requires Congress to approve funds approximately 4 years prior to the scheduled launch date to enable processing to begin. In these instances, the DOE budget to process $\mathrm{Pu}-238$ would be approved and funded by Congress; however, Congress would not approve the NASA budget for the launch until approximately a year immediately prior to the scheduled launch date. This enables DOE to perform the necessary planning and long lead time activities (such as $\mathrm{Pu}-238$ processing) to take place. Although there is uncertainty associated with final congressional approval of any NASA launch, Congress shows support for specific missions by approving the budget necessary for preparatory work.

Upon completion of the current campaign at SRS to process $\mathrm{Pu}-238$ oxide to be used by DOE to support NASA's Cassini mission, about 52 kilograms $(\mathrm{kg})$ of $\mathrm{Pu}-238$ will exist in the U.S. civilian inventory in various forms and isotopic contents that are mostly unusable as heat source fuel without further processing. This includes five $\mathrm{kg}$ recently purchased from Russia and received at the $S R S$ and includes an additional $10 \mathrm{~kg}$ from weapons returns (see section 1.1.2). To be available to satisfy projected mission requirements, these $\mathrm{Pu}-238$ materials, consisting mostly of recycle or scrap Pu-238 generated by pellet fabrication processes, safety testing activities, research and development programs, and quality assurance activities, must be processed at SRS facilities to remove chemical and isotopic impurities and to blend a resultant product with uniform $\mathrm{Pu}-238$ isotopic properties suitable for use. Because the steps involved in transforming $\mathrm{Pu}-238$ into assembled and fully qualified Radioisotope Thermoelectric Generators (RTGs) and Radioisotope Heater Units (RHUs) require several years, $\mathrm{Pu}-238$ of the required chemical and isotopic specifications must be made available years ahead of planned mission launches. DOE expects that 
any future $\mathrm{Pu}-238$ purchased from Russia would meet DOE specifications and would be able to be used directly in fuel pellet fabrication operations without the need for prior processing.

DOE needs to process the various forms of $\mathrm{Pu}-238$ that exist in the U.S. civilian inventory to specification Pu-238 based on NASA's requirements for RTGs and RHUs (Huntress, 1993). These requirements are shown in Table 1-1. Missions may be added to or deleted from this list through subsequent NASA planning. These requirements are known as flight or "fly-away" quantities and do not represent the total quantity of Pu-238 oxide necessary to support each mission. During $\mathrm{Pu}-238$ processing and fabrication, quantities of $\mathrm{Pu}-238$ oxide become unavailable for mission use due to requirements for analytical test samples, generation of Pu-238 scrap from product characterization and safety testing operations, fabrication of spare mission hardware, and products not meeting specifications and requiring recycle. Additionally, the $\mathrm{Pu}-238$ inventory is reduced by the natural decay of the material at $0.7 \%$ per year. Pu- 238 scrap materials generated through product characterization, safety testing, and fabrication programs may approach $25 \%$ of mission quantities. This Pu-238 scrap is not usable to satisfy mission requirements without additional processing into a uniform product.

\subsection{Background}

\subsubsection{Power Systems for NASA Missions}

The Atomic Energy Act of 1954, as amended, authorizes DOE to develop nuclear energy systems in support of other governmental organizations and for its own programs. The Act also authorizes DOE to produce such systems and directs DOE to take necessary actions to assure such systems are used in a safe manner. Under this charter, DOE has developed and provided Pu-238 fueled. radioisotope power systems for space and terrestrial missions for over 30 years. These power systems, known as RTGs, convert the heat from the natural decay of Pu-238 directly into electricity. RTGs fueled with $\mathrm{Pu}-238$ oxide have provided electrical power for a number of NASA space missions. Due to the relatively long half-life of Pu-238 (87.8 years) and the absence of any moving parts, RTGs provide long-term, reliable sources of electrical power to spacecraft and scientific experiments. In addition, $\mathrm{Pu}-238$ fueled light-weight RHUs can be used as localized heat sources on spacecraft. Historically, the HB-Line facilities at the SRS have been used to process $\mathrm{Pu}-238$ into an oxide powder to meet the required chemical, physical, and isotopic specifications for use in RTGs and RHUs.

The Galileo spacecraft, launched in 1989 to study Jupiter, and the Ulysses spacecraft, launched in 1990 to study the polar regions of the Sun, are powered by Pu-238 oxide fueled RTGs. These missions could not be accomplished without RTGs due to mission duration and distance from the Sun, rendering the use of chemical batteries or solar panels infeasible. To gain sufficient energy for its trajectory, the Ulysses spacecraft executed a gravity assisted flyby of Jupiter where the solar intensity is only four percent that of Earth. The scientific and technical knowledge gained from these and other missions is vastly expanding our knowledge of the universe. Pu-238 fueled RTGs have been used to provide electrical power to scientific instrument packages on the surfaces of both the Moon and Mars, and have provided electrical power to several Pioneer and Voyager spacecraft, the first spacecraft to reach the outer planets of Jupiter, Saturn, Uranus, and Neptune. These spacecraft provided the first detailed photographs of these distant planets, and the scientific data returned from these missions has broadened our understanding of the origins and evolution of the planets and planetary systems.

The NASA updated strategic plan for the Solar System Exploration Program identified a series of space exploration missions to achieve national goals, including a broadly based set of individual missions ranging from flybys, to orbiters and simple landers, to sophisticated robotic missions. A series of precursor missions to the Moon and Mars have also been considered. From this broad set of potential missions, NASA has identified missions for which Pu-238 fueled RTGs and RHUs 
National Aeronautics and Space Administration Missions 1

(modified from Brolin, 1993)

\begin{tabular}{|c|c|c|c|c|c|c|c|}
\hline Mission & $\begin{array}{l}\text { Year of } \\
\text { Launch } \\
\end{array}$ & $\begin{array}{c}\text { Number of } \\
\text { RTGs }\end{array}$ & $\begin{array}{c}\text { Total Pu-238 } \\
\text { Required } \\
\text { (kilograms) }\end{array}$ & $\begin{array}{c}\text { \% Activities } \\
\text { Completed at } \\
\text { SRS } \\
(3 / 95)^{4} \\
\end{array}$ & $\begin{array}{l}\% \text { Completion } \\
\text { of All Activities } \\
\text { to Support } \\
\text { Mission }(3 / 95)^{5}\end{array}$ & $\begin{array}{c}\text { Funding } \\
\text { Approved for } \\
\text { SRS to Process } \\
\text { Pu-238 } 6\end{array}$ & $\begin{array}{l}\text { Program Approved for } \\
\text { NASA Mission } 7\end{array}$ \\
\hline Cassini & 1997 & 3 & 26 & $95 \%$ & $60 \%$ & Yes & Yes \\
\hline Pluto Flyby & $\begin{array}{l}1999 \\
2000\end{array}$ & 1 & $\begin{array}{c}5^{8} \\
2.5^{8}\end{array}$ & $\begin{array}{l}\text { N/A } 8 \\
\text { N/A } 8\end{array}$ & $\begin{array}{l}0 \% \\
0 \%\end{array}$ & $\begin{array}{l}N / A^{8} \\
N / A^{8}\end{array}$ & $\begin{array}{l}\text { No (Expected 1998) } \\
\text { No (Expected 1999) }\end{array}$ \\
\hline $\begin{array}{l}\text { Mars } \\
\text { Environment } \\
\text { Survey } \\
\text { (MESUR) }\end{array}$ & $\begin{array}{l}2000 \\
2003\end{array}$ & $\begin{array}{c}4^{3} \\
4\end{array}$ & $\begin{array}{l}10 \\
10\end{array}$ & $\begin{array}{l}0 \% \\
0 \%\end{array}$ & $\begin{array}{l}0 \% \\
0 \%\end{array}$ & $\begin{array}{l}\text { Yes } \\
\text { Yes }\end{array}$ & $\begin{array}{l}\text { No (Expected 1999) } \\
\text { No (Expected 2002) }\end{array}$ \\
\hline Solar Probe & 2004 & 1 & 2.5 & $0 \%$ & $0 \%$ & Yes & No (Expected 2003) \\
\hline $\begin{array}{l}\text { Mars Sample } \\
\text { Returm Lander }\end{array}$ & 2005 & 2 & 5 & $0 \%$ & $0 \%$ & Yes & No (expected 2004) \\
\hline $\begin{array}{l}\text { Outer Planetary } \\
\text { Missions } 2 \\
\end{array}$ & after 2005 & 3 & 9 & $0 \%$ & $0 \%$ & Yes. & No (expected after 2005) \\
\hline
\end{tabular}

1 Missions, launch dates, and RTG requirements have been developed for planning purposes: Missions may be added or deleted from this list through subsequent NASA planning. Assumes use of current thermoelectric conversion technology.

2 Missions and power supplies are assumed for post-2000 planning purposes; missions have not been finalized.

3 Estimated number of power supplies, final configurations not yet determined.

4 Represents the current (3/95) percentage of Pu-238 that has been processed at SRS with respect to the total required for each mission.

5 Represents the current (3/95) percentage of activities that have been completed to support the mission.

6 Funding has been approved for SRS for process the required quantities of Pu-238 to support the missions when each overall mission is eventually funded. The funding for Pu-238 processing is not mission specific.

7 Funding for the overall mission is generally not approved by Congress until the year immediately prior to the launch date. Long lead time activities (such as Pu-238 processing) is funded separately and in advance of the overall mission funding.

8 DOE and NASA are currently evaluating the use of fuel from an existing RTG (spare RTG designated for previous Galileo and Ulysses missions). It is not anticipated that processing $\mathrm{Pu}-238$ will be required to support these missions.

9 The total quantity of Pu-238 required to be processed for post Cassini missions is $32.5 \mathrm{~kg}$. This does not include the additional quantities necessary for characterization, testing, and fabrication; however, it does take into account the $7.5 \mathrm{~kg}$. to support the two Pluto Flyby missions which is expected to come from a spare RTG, and the $4 \mathrm{~kg}$. of material that is expected to be purchased from Russia in 1995. 
are being considered. These planetary exploration and space science missions may not be feasible without the availability and use of Pu-238 fueled systems due to the distance from the Sun and mission duration, conditions precluding the use of solar panels or chemical batteries as electrical power sources. The numbers of RTGs and RHUs required for these missions were provided to DOE by NASA's Associate Administrator for Space Science (Huntress, 1993). These missions, which could require $70 \mathrm{~kg}$ of $\mathrm{Pu}-238$ through the year 2005 for flight power supplies, include Cassini, Pluto Fast Flyby, Mars Environmental Survey, Solar Probe, Mars Sample Return, and other outer planetary missions. DOE is currently processing Pu-238 in SRS HB-Line facilities to be available for use on the Cassini mission, scheduled for launch to Saturn in 1997. The current $\mathrm{Pu}-238$ inventory available for RTG use (including $5 \mathrm{~kg}$ purchased from Russia) is $68.2 \mathrm{~kg}$. Cassini mission flight requirements will reduce this inventory by $26 \mathrm{~kg}$. Additionally, approximately $10 \mathrm{~kg}$ of $\mathrm{Pu}-238$ from weapons returns is expected to be available for use. Thus about $52 \mathrm{~kg}$ would be available for processing following completion of the current operation for the Cassini mission. These quantities do not reflect natural radioactive decay or the $\mathrm{Pu}-238$ required for testing as discussed in Section 1.0, or losses due to the efficiency of the process lines.

In 1993, DOE prepared an EA (DOE, 1993a) that evaluated the potential environmental impacts of importing up to $40 \mathrm{~kg}$ of Pu-238 from Russia over the next five years to supplement the current U.S. inventory. A Finding of No Significant Impact was issued on June 25, 1993. In February of 1994, the first $5 \mathrm{~kg}$ of Pu-238 purchased from Russia was received by DOE at the Savannah River Site. This first $5 \mathrm{~kg}$ of $\mathrm{Pu}-238$ contains impurities which do not meet DOE's specification requirements; therefore, additional processing is necessary.

A second purchase of approximately $4 \mathrm{~kg}$ has been approved for purchase during early Fiscal Year 1995. This material will be sent directly to the Los Alamos National Lab because DOE expects that additional processing will not be necessary prior to fuel pellet fabrication. The contract with Russia provides options for the purchase of an additional $31 \mathrm{~kg}$. Additional purchases depend on funding availability and administration approval; however, due to budgetary limitations in Fiscal Years 1995-1997, DOE does not anticipate purchasing any further $\mathrm{Pu}-238$ from Russia under this existing contract which expires in 1997. If additional Pu-238 is purchased from Russia, DOE does not anticipate processing of the material in HB-Line prior to use.

\subsubsection{Pu-238 from Weapons Returns}

Quantities of Pu-238 exist in nuclear weapons systems scheduled for dismantlement as a result of recent Presidential nuclear weapons policy declarations (dated September 27, 1991; January 28, 1992; and June 16, 1992). This Pu-238 is referred to as "weapons return". An evaluation was performed to determine if any suitable weapons return $\mathrm{Pu}-238$ would be available for processing during the planned time frame of the proposed action. DOE received information confirming that approximately $10 \mathrm{~kg}$ of $\mathrm{Pu}-238$ from weapons return will be available. DOE is considering processing this material, provided the properties meet the requirements necessary for use in space power systems.

\subsubsection{Recent HB-Line Operations}

This EA is being prepared to assess the environmental impacts of operating the HB-Line Facility and Frame Waste Recovery units following completion of current operations which support NASA's Cassini mission. It is being prepared as a result of a settlement of a lawsuit filed against the Department of Energy by the Energy Research Foundation (ERF) of Columbia, South Carolina, on January 4, 1993. Operations were assessed in an EA prepared in 1991 (DOE, 1991); a Finding of No Significant Impact was issued in July 1991 and HB-Line resumed operations. 
Seven days after restart, operations in HB-Line were suspended due to radiological contamination of five workers resulting from conduct of operations inadequacies involving Pu-238 scrap. stored in the HB-Line vault. Operations resumed in October 1991. One month later operations were suspended again due to an inadvertent transfer of zirconium within the HB-Line. Operations then resumed in December 1991. In March 1992 operations in HB-Line and H-Canyon were suspended because of a safety question concerning the air exhaust stack liner. There was concern that the stack liner (not the stack) would collapse in the event of a design basis earthquake and prevent proper ventilation. These concerns were resolved in December 1992 with adequate compensatory measures put in place to ensure proper ventilation in the event the stack liner collapsed.

Operations resumed in January 1993 and have continued to the present. In June 1994 the HCanyon building steam system was damaged by failure of a steam isolation valve. This occurrence caused the Frame Waste Recovery process to be shut down. Consequently HB-Line operations were suspended and the down time was utilized for maintenance activities. Operations have since resumed. Regular shipments of $\mathrm{Pu}-238$ oxide have been made to the Los Alamos National Laboratory, the second site involved in the process of producing RTGs.

Prior to restart to support the Cassini mission, the Defense Nuclear Facilities Safety Board (DNFSB) had raised concerns about the Operational Readiness Reviews (ORR's) that were conducted prior to startup in June 1991. In response to the DNFSB recommendations, Westinghouse Savannah River Company (WSRC) and DOE conducted new reviews to determine if the facility was safe to start and operate. DOE identified items that required resolution before restarting the facility. The findings included items such as inadequate conduct of operations, and inadequate training, qualifications, certification, and oversight by the DOE Savannah River Operations Office (SR) facility representative, and inadequate audit closure of corrective actions for restart. All findings were corrected and validated as closed by WSRC, DOE-SR, and the DOE-HQ Office of Nuclear Safety. The DNFSB held a public hearing in Aiken, South Carolina on these issues in December, 1992. Operations resumed January 7, 1993.

The Energy Research Foundation of Columbia, South Carolina, filed suit against the Department on January 4, 1993. The complaint sought relief in the form of a declaration that the Department was in violation of NEPA for failing to prepare an Environmental Impact Statement (EIS) for HBLine operations and an injunction prohibiting the Department from starting up HB-Line until an EIS was prepared, circulated for comment, and considered in the decision-making process. In a settlement agreement dated November 17, 1993, DOE and ERF agreed to the preparation of this EA to address issues raised by ERF and the future operation of HB-Line.

DOE is currently preparing EISs which are related to operation of the HB-Line. The Waste Management EIS (Draft published January 27, 1995) addresses an SRS strategy for management of waste resulting from past, current, and future SRS operations. Wastes generated as a result of the proposed action described in this EA would be considered in the Waste Management EIS. The Interim Management of Nuclear Materials EIS (Draft published March 17, 1995) and the F-Canyon Plutonium Solutions EIS (Final published December 30,1994) address operations to process any materials for which the Department has an identified programmatic need and materials that are determined to represent an unacceptable risk, stored in their current form, to SRS workers, the public, or the environment. 


\subsection{PROPOSED ACTION AND ALTERNATIVES}

\subsection{Proposed Action}

The proposed action is for DOE to continue to operate and maintain the Pu-238 processing facilities at the Savannah River Site (SRS) and process of Pu-238 scrap material into a usable oxide powder to preserve the capability to support NASA missions. A flight quantity of approximately $32.5 \mathrm{~kg}$ of $\mathrm{Pu}-238$ needs to be processed into a usable product to satisfy current projections of $\mathrm{Pu}-238$ needed to support post Cassini NASA missions as indicated in Table 1-1. Additional quantities would be required for analytical samples, characterization, and testing. Processing of the Pu-238 purchased from Russia and shipped to SRS in 1994 is included in the proposed action. This five $\mathrm{kg}$ of $\mathrm{Pu}-238$ requires processing because it contains impurities which do not meet DOE's specification requirements. The proposed action also includes processing approximately $10 \mathrm{~kg}$ of $\mathrm{Pu}-238$ from weapons returns, provided the properties meet the required properties necessary for use in space power systems. The proposed action does not include disposition of the HB-Line facility and Frame Waste Recovery process; DOE will prepare additional NEPA reviews when proposals for decontamination and decommissioning or alternative uses are prepared.

The proposed action includes shipment of $\mathrm{Pu}-238$ scrap material ( $\mathrm{Pu}-238$ in forms and isotopic content that is not usable as heat source fuel without processing) from DOE's Mound Laboratory, Miamisburg, Ohio (Mound), and the Los Alamos National Laboratory, Los Alamos, New Mexico (LANL), to the Savannah River Site.

DOE's Office of Nuclear Energy is conducting a study to evaluate the capability of facilities to ensure that infrastructure will be in place to support long-term RTG requirements. The study involves evaluations of LANL, Mound, Oak Ridge, the Idaho National Engineering Laboratory (INEL), and the Hanford Site. Therefore, storage of Pu-238 at Savannah River prior to shipment to the appropriate site is considered part of the proposed action evaluated in this EA. Should a new Pu-238 mission be proposed for Oak Ridge, INEL, or Hanford, or a continued Pu-238 mission proposed for Mound or LANL, analysis of Pu-238 transportation from the Savannah River Site to the appropriate site and any required storage at that site would be included in the NEPA review prepared for that proposal.

Fabrication of the Pu-238 heat source units for NASA's Cassini mission at the Los Alamos National Laboratory from the plutonium oxide produced at SRS was addressed in an Environmental Assessment completed in 1991. The EA (DOE, 1991) was the basis for a Finding of No Significant Impact (FONSI) issued in July 1991 .

The proposed action would include operation of the following processes located within the H-Area Canyon and B-Line Buildings:

- $\quad$ Scrap Recovery Facility (HB-Line Phase I). This facility would be used to dissolve and blend existing inventories of Pu-238 oxide and Pu-238 scrap materials.

- $\quad$ Plutonium Oxide Facility (HB-Line Phase III). This facility would be used to convert plutonium nitrate solution to a powder oxide form via a precipitation process.

- Frame Waste Recovery (FWR). This facility located within H-Canyon would be used to purify the plutonium solutions using an ion exchange process.

- HB-Line Vault. This facility would be used to safely store Pu-238 product material.

- Transportation of scrap Pu-238 material from DOE Mound Plant and Los Alamos National Laboratory to the Savannah River Site. 


\subsection{Alternatives to the Proposed Action}

\subsubsection{No Action}

Under the no action alternative, the $\mathrm{Pu}-238$ processing facilities would continue to operate until completion of the campaign for the Cassini mission, estimated to be completed by June 1995 . Once this mission had been fulfilled, operation of these facilities to support $\mathrm{Pu}-238$ processing would be terminated. This alternative does not allow for the processing of material for future use as a heat source in RTGs or RHUs.

\subsubsection{Alternative Processing Facility}

This alternative would involve processing Pu-238 material in facilities other than HB-Line. Except as discussed below, because no other such facilities currently exist construction of new facilities would be required. Because this would be very costly, and because process efficiency or safety of the technology incorporated in the HB-Line facilities would not be improved upon, this is not considered a reasonable alternative.

\subsubsection{Alternative Vault Storage Facility}

This alternative would involve using an SRS vault other than the HB-Line vault for storage of processed $\mathrm{Pu}$-238. DOE investigated three existing SRS vaults, all located in F-Area: the Building $247-\mathrm{F}$ vault, vaults in Building 235-F, and the Plutonium Storage Facility located in the F-Canyon. Each of these facilities would require extensive modification to accommodate storage of $\mathrm{Pu}-238$, including installation of equipment for cooling the storage containers. The HB-Line vault is currently fully capable of storing Pu-238; therefore DOE does not consider modification of other facilities a reasonable alternative.

\subsubsection{Processing at the National Laboratories}

In the United States (U.S.), only the SRS has a current capability to chemically process Pu-238 into the usable specification oxide powder form. The Los Alamos National Laboratory (LANL) has proposed adding the capability to conduct small scale $\mathrm{Pu}-238$ processing for scrap recovery in the existing plutonium handling facility. New equipment and facility modifications, followed by extensive testing and demonstration, would be required prior to the commencement of $\mathrm{Pu}-238$ processing at LANL. A new $\mathrm{Pu}-238$ processing capability at LANL would be limited to approximately 100 to 300 grams per month, compared to SRS's 2000 to 4000 grams per month capacity. Due to the necessary equipment procurement and facility modifications, testing and demonstration requirements, start-up approvals, and limited capacity for Pu-238 processing at LANL, this alternative could delay the availability of specification $\mathrm{Pu}-238$ for use in projected mission applications, and is not considered by DOE to be a reasonable alternative to completing the processing of the U.S. Pu-238 inventory at SRS using existing, operating facilities.

\subsubsection{Purchase of Pu-238 from Foreign Nations}

This alternative would involve purchasing $\mathrm{Pu}-238$ from foreign nations rather than processing the U.S. Pu-238 inventory into specification oxide powder using SRS facilities. Discussions with France and Great Britain have concluded that kilogram quantities of $\mathrm{Pu}-238$ could be made available by these countries sometime after 1999, but only after significant investment in new facilities. The U.S. has a contract in place with Russia for the purchase of up to $40 \mathrm{~kg}$ of Pu-238 through 1997. The U.S. purchased the first $5 \mathrm{~kg}$ of Pu-238 under this contract in 1994. This first $5 \mathrm{~kg}$ is in storage at the SRS pending processing as part of this proposed action. The necessary approvals and funding have been received for a second purchase of approximately $4 \mathrm{~kg}$. DOE expects to complete this second purchase in early 1995 . The $\mathrm{Pu}-238$ oxide powder in the second 
purchase should not require chemical processing in U.S. facilities prior to use in fuel pellet fabrication operations. Funding for additional purchases of $\mathrm{Pu}-238$ is not included in the planned DOE budgets for fiscal years 1995 and 1996. Due to these budgetary limitations, DOE does not anticipate purchasing any further $\mathrm{Pu}-238$ from Russia under the existing contract which expires in 1997. Therefore, the foreign purchase alternative is not considered viable if DOE is to be responsive to NASA's requirements as they develop in the near term. The existing U.S. Pu-238 inventory needs to be processed into a usable form to support post Cassini NASA missions as indicated in Table 1-1.

\subsubsection{Alternative Packaging and Storage of Pu-238}

Under this alternative, the pu-238 processing facilities would continue to operate until completion of the campaign for the cassini mission, estimated to be completed by june 1995 . Once this mission had been fulfilled, these facilities would operate to stabilize pu-238 scrap material stored at the srs to meet the long-term storage criteria for plutonium (doe, 1994). The pu-238 scrap could generally be stabilized by simply heating and repackaging the material. This would consist of a glovebox being added to an existing or new facility (i.E., Proposed actinide packaging facility) to heat plutonium oxide and to package oxide and metal in a non reactive atmosphere without the use of plastic wrapping. The packaged material would then be placed in a srs vault. This alternative would ensure that material remaining at the SRS would meet the long-term storage criteria; however, this alternative alone is not considered if DOE is to be responsible to NASA's requirements.

\subsection{OPERATION DESCRIPTION}

The plutonium processing facilities are located on top of the H-Area Canyon Building 221-H (Figure 3-1) and include the Scrap Recovery Facility (Phase I) and the Plutonium Oxide Facility (Phase III). The Frame Waste Recovery process is located within the $221-\mathrm{H}$ building. The HBLine facility also houses a vault for the storage of $\mathrm{Pu}-238$ oxide product and scrap material. A material flow diagram for the Pu-238 operations described in this section is given in Figure 3-2. $\mathrm{H}-$ Area is depicted in relation to surrounding areas in Figure 4-1.

The HB-Line facility proposed for operation under this action was built on top of the Canyon in the early 1980s, replacing an existing facility located on the 3rd and 4th levels of the H-Canyon. The HB-Line facility operated between 1985 and 1987 . Operations in the HB-Line facility to fulfill the Cassini mission requirements resumed in July 1991.

\subsection{Facility Description}

The canyon building is a blast resistant reinforced-concrete structure, 835 feet long, 122 feet wide, and 66 feet high, with 52 feet extending above grade. Processing equipment is isolated from the operating personnel, the environment, and the public in two parallel canyons (hot canyon and warm canyon) 15 feet wide at the bottom and 30 feet wide at the top, separated by a central operating and service section. The HB-Line facilities were constructed on top of the H-Canyon building and the Frame Waste Recovery process occupies a small area within the hot canyon of the $\mathrm{H}$-Canyon building. A figure of the canyon building including $\mathrm{HB}$-Line is provided below in Figure 3-1. Figure 3-2 is a Pu-238 material flow diagram

\subsubsection{HB-Line Facilities}

The facilities were designed incorporating the lessons learned from over twenty years of operating experience. The HB-Line Facility incorporates improvements in engineering controls for nuclear safety; cabinet integrity and engineered barriers to minimize potential for personnel exposure to 


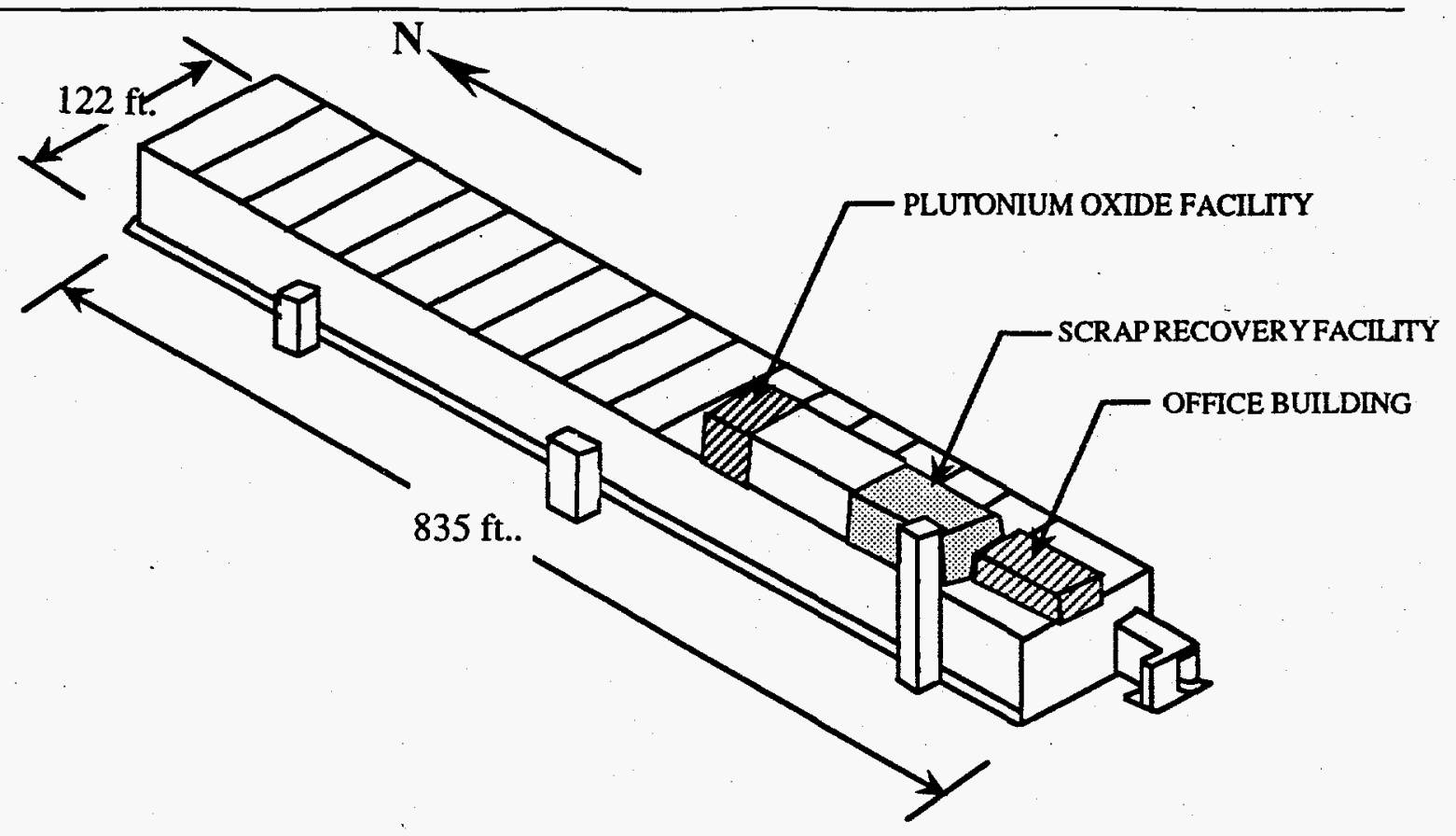

Figure 3-1. H-Canyon Building and HB-Line Facilities.

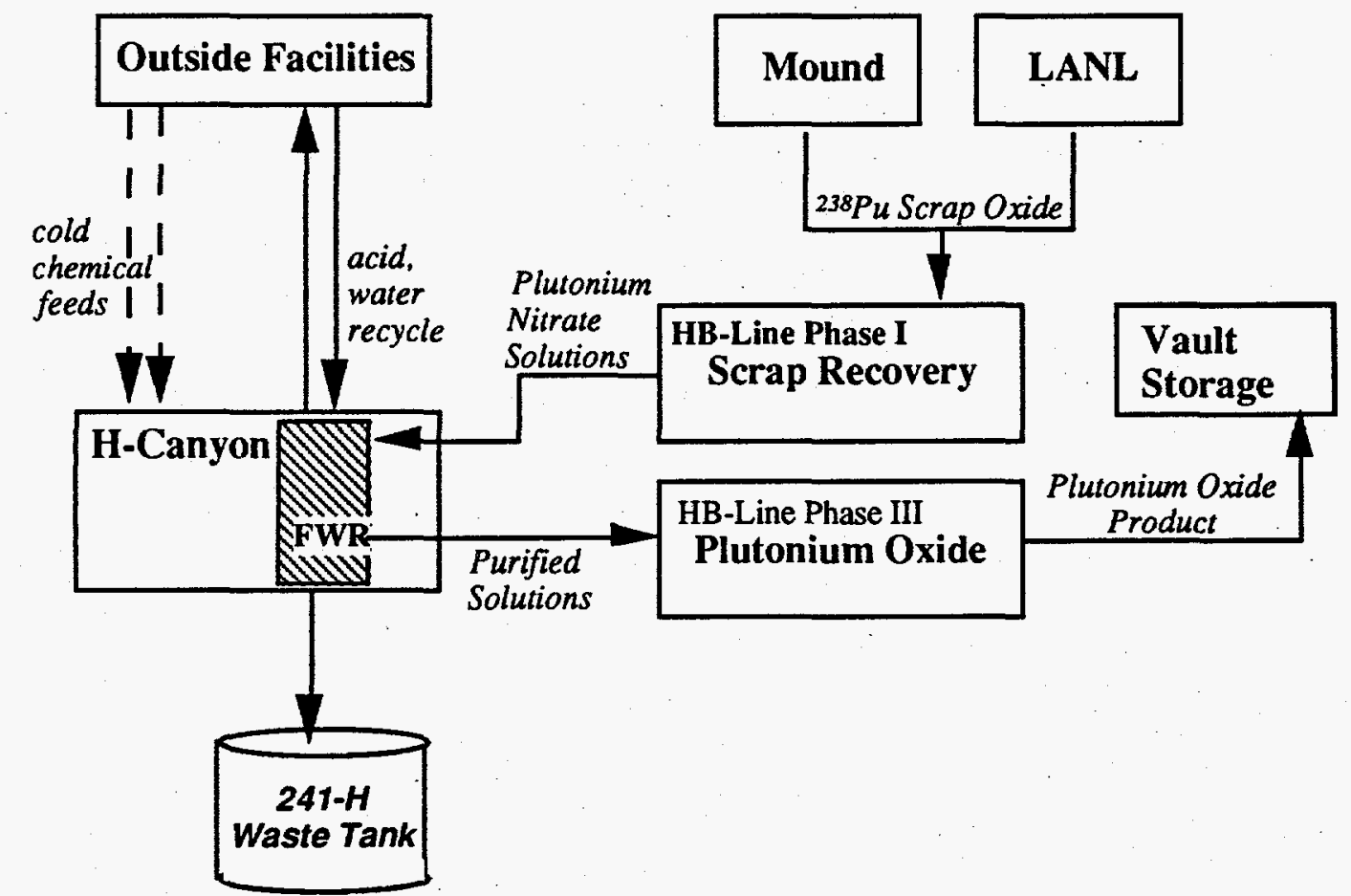

Figure 3-2. Pu-238 Material Flow Diagram 
airborne contamination; shielding and remote operations to decrease radiation exposure; and equipment and ventilation design. Confinement and shielding are provided by glove boxes, which are exhausted through two stages of independently testable High Efficiency Particulate Air (HEPA) filters. Process service systems (electrical, air, water, HVAC, and instruments and controls) are designed with engineered features (fail-safe, redundancy, multiplicity) to prevent the escalation of possible abnormalities.

The processing of $\mathrm{Pu}-238$ begins with dissolving $\mathrm{Pu}-238$ oxides in various forms. This takes place in the Scrap Recovery Facility in what are called "glove boxes". The glove box sections contain the charge preparation areas, valves, product filters, most of the piping, and other miscellaneous equipment. Glove boxes are cabinets constructed of stainless steel-lead-waterstainless steel with acrylic/lead glass windows. Operators have access through glove ports such that the operator never breaches containment of the glove box and process area. The glove ports have also been designed to allow replacement of the gloves with a much reduced chance of breaching containment. While working in the glove boxes, all operators and personnel in the process rooms are required to wear protective clothing and respiratory protection as an additional precaution against external and internal contamination.

\subsubsection{Frame Waste Recovery Process}

The Frame Waste Recovery process is located within the H-Canyon "hot canyon" where the more highly radioactive, remote operations are carried out. The process consists of a column feed tank which receives solutions from the Scrap Recovery facility, an ion exchange column, and a product hold tank from which solutions are sent to the Plutonium Oxide facility.

\subsubsection{HB-Line Vault}

The storage vault, located in $221-\mathrm{H}$ in the HB-Line facility, is constructed with reinforced concrete walls, ceilings, and floors. The vault has stainless steel product storage tanks which house storage locations in a critically safe array for product containers. These stainless steel tanks contain water to cool the stored containers. The water is then cooled by the HB-Line cooling water system. The HB-Line cooling water system is a non-contact internal recirculating "loop" which is independent of any other cooling water system.

The vault complies with the requirements of DOE Order 5632.2A, Physical Protection of Special Nuclear Material and Vital Equipment. Vault security features include two independent door locks, card reader personnel accountability system, door tamper indications, motion detectors, and cameras. The vault contains ceiling mounted smoke detectors which are designed to automatically activate and release the fire suppression system and shut down the ventilation exhaust upon actuation. The vault also contains a set of Nuclear Incident Monitors for detection of a nuclear incident and actuation of an alarm bell to alert personnel.

\subsection{Processing Description}

\subsubsection{Scrap Recovery Facility (HB-Line Phase I)}

Figure 3-3 pictures a simplified flow diagram for processing $\mathrm{Pu}-238$ through $\mathrm{HB}-\mathrm{Line}$ and the Frame Waste Recovery Unit. The processing of $\mathrm{Pu}-238$ begins with dissolving $\mathrm{Pu}-238$ scrap in various forms. This takes place in the Scrap Recovery Facility in what are called "glove boxes". The oxide feed material is removed from its unique container inside the glove box and put into a dissolver. The scrap oxide is dissolved with nitric acid and a fluoride catalyst. The resulting nitrate solution is then filtered and sent to a hold tank before being transferred to the Frame Waste Recovery unit in the H-Canyon. 


\subsubsection{Frame Waste Recovery (FWR) Process}

The purpose of the Frame Waste Recovery (FWR) system is to purify and concentrate Pu-238 for processing and to transfer the associated waste solutions to the waste tanks.

Solutions entering the remotely operated FWR process are chemically adjusted with nitric acid $\left(\mathrm{HNO}_{3}\right)$, ferrous sulfamate, and hydrazine in the column feed tank. The plutonium is then oxidized by heating the solution to a temperature between $50-60^{\circ} \mathrm{C}$ for thirty minutes.

The adjusted solutions are then pumped through an ion exchange column where $\mathrm{Pu}-238$ is adsorbed onto the resin. The resin bed is washed with nitric acid to remove fission products and chemical impurities. The Pu-238 is then removed from the resin column and sent to a hold tank until transferred to the Plutonium Oxide Facility for further processing.

Acid solutions containing the fission products and chemical impurities from the resin column are evaporated to recover the acid. The concentrated unevaporated solutions are neutralized and transferred to the 241-H Tank Farm Facility as radioactive liquid waste. Table 5-4 provides the volume estimates for this waste stream.

\subsubsection{Plutonium Oxide Facility (HB-Line Phase III)}

The purified Pu-238 solution from FWR is then returned to the Plutonium Oxide Facility for processing into an oxide. The nitrate solution is adjusted with ascorbic acid and hydrazine. The adjusted nitrate solution is then added to the oxalic acid in a precipitator to precipitate the $\mathrm{Pu}-238$. The precipitated $\mathrm{Pu}-238$ is filtered and washed using in-line filter boats. The filter boat containing the oxalate cake is then transferred to the calcining furnace. The oxalate cake is then calcined using ultra-pure oxygen-16 to reduce neutron emissions from the oxide. The powder is then loaded into a stainless steel shipping container for transfer to LANL for use in fuel pellet fabrication operations.

\subsection{Management \& Operation}

The HB-Line facility and FWR are managed and operated by the Westinghouse Savannah River Company (WSRC) under contract to DOE. Operation of the facilities is conducted in accordance with requirements established by DOE Orders. The Department of Energy uses DOE Orders to set standards, criteria, and requirements for operation of its facilities in compliance with regulations and law. WSRC then implements the DOE Orders through formalized procedures. The facilities are periodically reviewed and assessed against these requirements by the Savannah River Operations Office (SR), the Energy Department's Office of Environment, Safety and Health (EH), and independently of DOE by the Defense Nuclear Facility Safety Board (DNFSB).

\subsection{Description of Transportation Activities}

The proposed action includes receipt of scrap plutonium oxide shipments from Mound and Los Alamos National Laboratory (LANL). A maximum of 10 and 35 kilograms of material would be received from Mound and LANL, respectively (Jacobson 1994a). These quantities include up to $10 \mathrm{~kg}$ of weapons return Pu-238 from LANL. Product Pu-238 oxide would be stored at SRS (Jacobson 1994b).

Shipment of scrap Pu-238 material to the Savannah River Site would be made by DOE Albuquerque Operations Office's Transportation Safeguards Division (TSD). The shipments would be made in accordance with U. S. Department of Transportation regulations (49 CFR 171 179 ) and DOE Orders. 


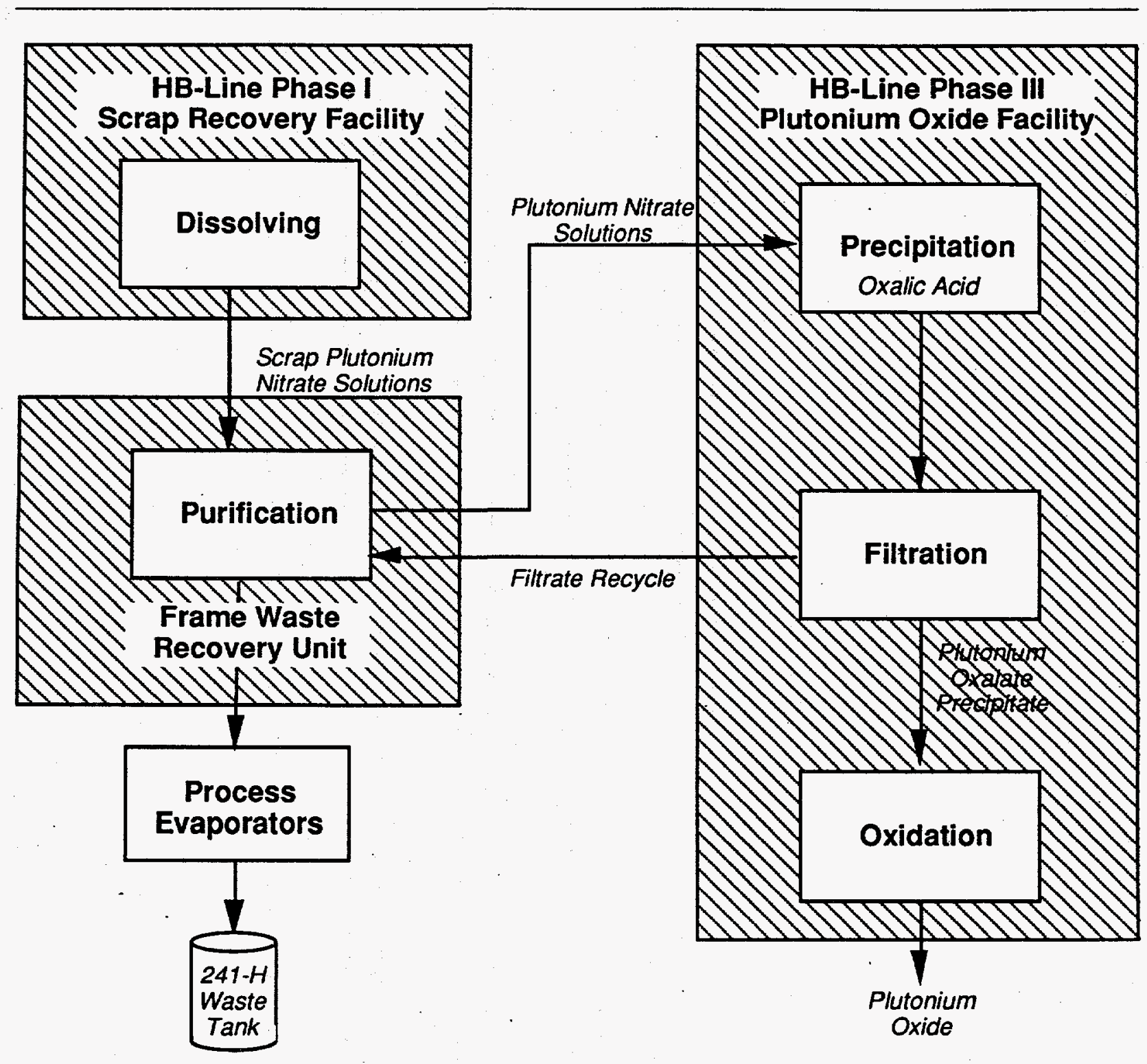

Figure 3-3. Pu-238 Process Flow Diagram. 
Pu-238 material would be shipped in Type B containers carried in Safe Secure Trailers (SSTs) operated by TSD. The material to be shipped would be packaged in Department of Transportation (DOT) Type B containers prior to shipment. The Type B shipping containers expected to be used for shipments under the Proposed Action are the "5320" container (Jacobson 1994a, 1994b) although the Type B Mound "1KW" container may be used (Jacobson 1994a). The SST transporting the Pu-238 would be accompanied by guarded escort enroute and its traveling times are limited, thereby minimizing the occurrence of potential accidents.

The DOE-TSD safety standards effectively minimize the probability of accidents. DOE-TSD has never experienced an accident causing a fatality or release of radiological material in over 70 million miles of highway transport; the DOE-TSD safety record is several times better than that of the commercial trucking industry (DOE, 1993). Shipments of materials are constantly monitored and tracked to ensure prompt attention and proper notification of authorities in the event of an accident. If an accident should occur, drivers are trained to make a preliminary assessment of the situation. If necessary, radiological assistance teams are available to help mitigate consequences of the accident.

\subsection{AFFECTED ENVIRONMENT}

A comprehensive discussion of SRS and environs is presented in the Reactor Operation Environmental Impact Statement (DOE, 1990a), and in the Reactor Operation Environmental Information Documents, Volumes I; II, \& III (WSRC, 1989a; WSRC, 1989b; WSRC, 1989c). The affected environments highlighted below are those areas that are most likely to be impacted by the proposed action.

\subsection{Geography, Demography, and Socioeconomics}

The SRS encompasses approximately 775 square kilometers ( 300 square miles) adjacent to the Savannah River principally in Aiken and Barnwell counties in southwestern South Carolina. In 1990 , the population of the six counties surrounding the SRS was 425,607 including a work force of 208,984. Approximately 20,000 SRS workers, or about 9 percent of the available regional work force live in the six-county area. The most recent socioeconomic survey of the six-county SRS area of influence (NUS, 1992) contains additional information.

The HB-Line and FWR facilities are located in H-Area on the Savannah River Site. Figure 4-1 shows H-Area in relation to SRS boundaries and the surrounding areas.

\subsection{Radiation Environment}

Natural radiation sources contribute about 315 mrem per year, or 83 percent of the annual radiation dose of 380 mrem received by the average individual residing in the SRS regional area from all sources. Other contributions to individual radiological dose are from medical applications and consumer products which contribute 54 mrem (14 percent) and 10 mrem ( 3 percent), respectively. The SRS total radiation dose contributes less than one percent of the total annual dose received by the maximally exposed individual (WSRC, 1993a).

\subsection{Waste Management}

The SRS generates liquid, solid, and semisolid wastes originating in reactor and support facility operations, maintenance, and renovation. This EA describes the wastes that would be generated as a result of implementation of the proposed action and the potential impacts of those waste streams on existing SRS waste management capabilities. NEPA review of SRS waste management 
activities has been and currently is being prepared separate from this EA. On April 6, 1994, DOE announced its intent to prepare an EIS to address the generation, minimization, treatment, storage, and disposal of high-level, low-level, transuranic, mixed, and hazardous waste at the SRS. The Draft Savannah River Site Waste Management EIS (DOE, 1995) was published on January 27, 1995. DOE prepared an EIS on the Defense Waste Processing Facility (DWPF) in 1982 (DOE, 1982) and published a Supplemental DWPF EIS on November 24, 1994 (DOE, 1994a) to address system changes that have been implemented since 1982 and their environmental impacts. These EISs address the management of waste streams including those that would be generated as a result of the proposed action described in this EA.

\subsection{ENVIRONMENTAL CONSEQUENCES OF THE PROPOSED ACTION}

\subsection{Normal Facility Operations}

The environmental consequences presented below represent the expected annual impact of operating HB-Line and the Frame Waste Recovery unit.

\subsubsection{Socioeconomics}

The HB-Line is an existing facility that has been operating in several stages since 1985. Since no modernization, construction activities, or additional employees would be required to implement the proposed action, the only socioeconomic impact would be from the operational and maintenance personnel required to run the facility. Present plans call for approximately 200 operational and support employees to operate and support HB-Line Phases I \& III and the Frame Waste Recovery unit. These employees are part of the existing SRS operational work forces and are now working to complete the Pu-238 fuel processing requirements for the Cassini mission. SRS currently employs approximately 20,000 workers. Because no socioeconomic impacts are expected as a result of the proposed action, no differential impacts on minority or low income communities would result.

\subsubsection{Ecology and Cultural Resources}

No ecological or cultural resource impacts would be expected from the proposed action. The new HB-Line facility was constructed in 1985 and is part of a previously developed and highly industrial area. As a result, no endangered species, wetlands, cultural resources or other environmentally sensitive resources will be directly or indirectly impacted by the proposed action.

\subsubsection{Air Emissions}

Processing $\mathrm{Pu}-238$ results in releases of both radiological and non-radiological pollutants. The non-radiological pollutants are nitric acid, nitrogen oxides $\left(\mathrm{NO}_{\mathrm{x}}\right)$, di-nitrogen oxide $\left(\mathrm{N}_{2} \mathrm{O}\right)$, hydrogen fluoride (HF) and carbon monoxide (CO). Table 5-1 lists the estimated emissions for these non-radiological pollutants per gram of Pu-238. The estimated totals are also provided and are based upon current mission requirements from Table 1-1.

Estimated annual atmospheric radiological releases typical of HB-Line operation are shown in Table 5-2. The estimate is based on 1993 actual emissions from the 291-H stack (WSRC, 1993b). Methods and models used for dose calculations are provided in the SRS Environmental Report (WSRC, 1993a). Since this is the emission source for H-Canyon (including Frame Waste Recovery) in addition to the HB-Line facilities, the estimate is considered typical for normal operation. The cumulative SRS atmospheric dose including operation of HB-Line and FWR would be less than 3\% of the DOE annual limit of 10 mrem (DOE 1990b). The effects of radiological dose are analyzed in Section 5.3. 


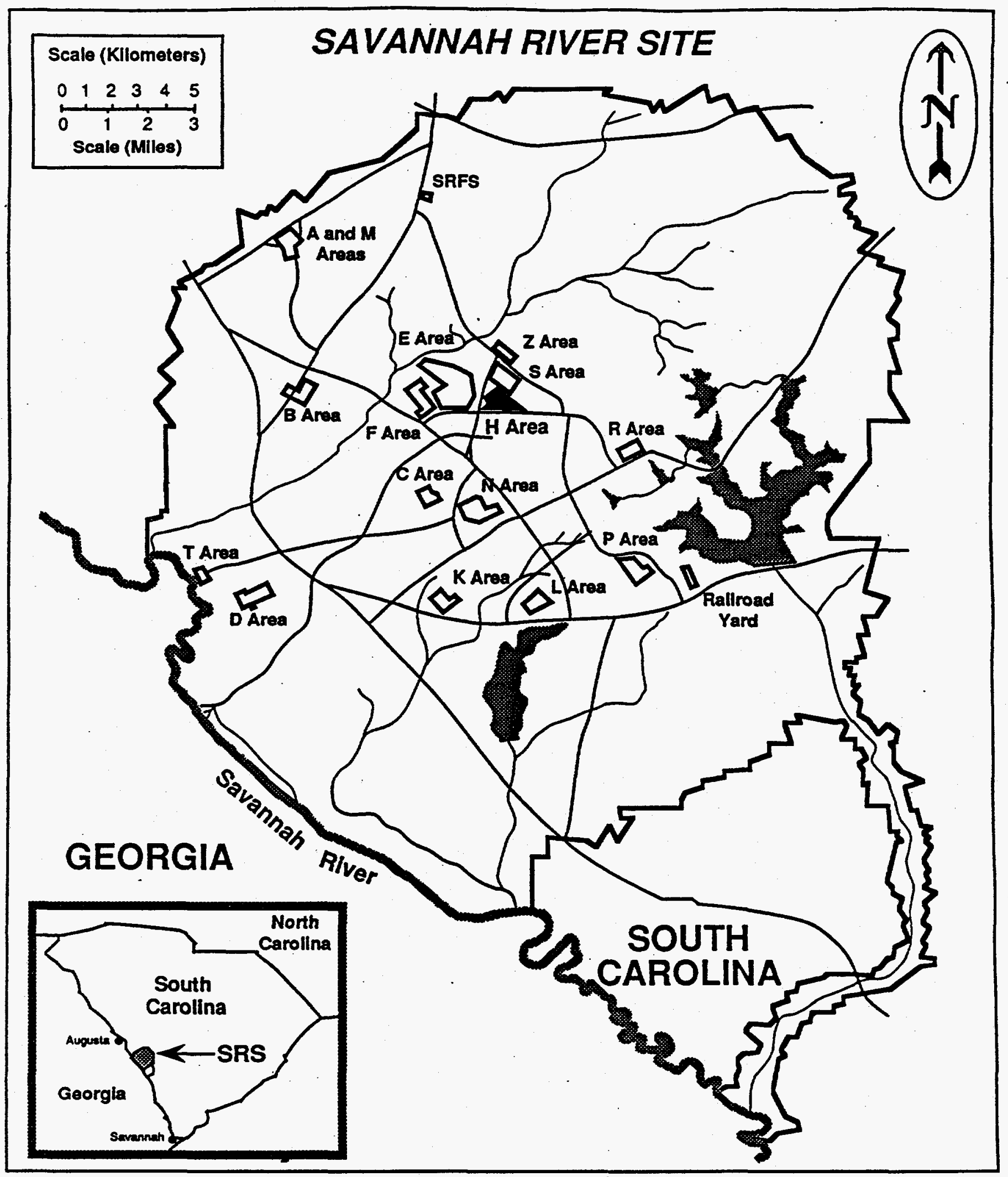

Figure 4-1. Operational Areas on SRS. 
The 221-H and HB-Line ventilation systems control the spread of radioactive material to clean areas by constantly pulling air from areas of lower contamination to areas of higher contamination. This air is filtered and then released through the $291-\mathrm{H}$ stack. These building ventilation systems would remain operational independent of Pu-238 production needs. Therefore, emissions from the 291-H stack would continue to contribute to the off-site dose from SRS. Under the "No Action" alternative, emissions for HB-Line processing would continue until completion of the Cassini mission, estimated to be completed by June 1995, with emissions dropping off slightly after this when operations to support the Cassini mission would cease.

Table 5-1

Non-Radiological Air Pollutants for Processing Pu-238

\begin{tabular}{lcc}
\hline \hline Pollutant & $\begin{array}{c}\text { Estimated Actual } \\
(\mathrm{lbs} / \mathrm{g} \mathrm{Pu}-238)\end{array}$ & $\begin{array}{c}\text { Estimated Total based on } \\
\text { mission requirements } \\
(1) \\
\text { (Total lbs) }\end{array}$ \\
\hline \hline Nitric Acid & $4.49 \times 10^{-05}$ & $2.33 \times 10^{0}$ \\
$\mathrm{HF}$ & $7.85 \times 10^{-07}$ & $4.08 \times 10^{-02}$ \\
$\mathrm{NO}$ (Total) & $9.59 \times 10^{-04}$ & $4.99 \times 10^{+01}$ \\
$\mathrm{NO} 2$ & $5.82 \times 10^{-04}$ & $3.03 \times 10^{+01}$ \\
$\mathrm{~N}_{2} 0$ & $3.77 \times 10^{-04}$ & $1.96 \times 10^{+01}$ \\
$\mathrm{CO}$ & $2.38 \times 10^{-02}$ & $1.24 \times 10^{+03}$ \\
\hline
\end{tabular}

(1) An estimated $52 \mathrm{~kg}$ is currently available for processing

Table 5-2

Atmospheric Radiological Emissions

Maximally Exposed

DOE

Offsite Individual

Dose Limit

[mrem/year]

[mrem/year]

\begin{tabular}{lcc}
\hline \hline H-Area Main Stack & 0.005 & N/A(1) \\
SRS Total & 0.229 & 10 \\
\hline
\end{tabular}

(1)Limit applies to the entire site release and not to each source. 


\subsubsection{Surface Water Effluents}

Estimated annual liquid releases typical of HB-Line operation are shown in Table 5-3. The estimate is based on 1993 actual emissions from H-Area (WSRC, 1993b). Methods and models used for dose calculations are provided in the SRS Environmental Report (WSRC, 1993a). Since several facilities drain into the same outfall it is difficult to isolate the contribution from only the HB-Line and FWR facilities. Therefore, the estimated dose from $\mathrm{H}$-Area is considered to be bounding since it includes other facilities. The total SRS cumulative dose from water pathways would remain less than $1 \%$ of the DOE annual dose limit of $4 \mathrm{mrem}$ through water pathways. The effect of radiological dose to individuals is discussed below in Section 5.3.

Effluent from Building 221-H from normal operation of HB-Line and FWR generally includes rainwater runoff, non-process cooling water, and condensate from steam lines or from Heating, Ventilation, and Air Conditioning (HVAC) systems. Liquid effluents associated with the HCanyon building are currently permitted by the South Carolina Department of Health and Environmental Control (SCDHEC) under the National Pollution Discharge Elimination System (NPDES) permit number SC0000175.

Table 5-3

Liquid Radiological Effluents

\begin{tabular}{ccc}
\hline \hline & $\begin{array}{c}\text { Maximally Exposed } \\
\text { Offsite Individual } \\
\text { [mrem/year] }\end{array}$ & $\begin{array}{c}\text { DOE } \\
\text { Dose Limit } \\
\text { [mrem/year] }\end{array}$ \\
\hline \hline H-Area & 0.0017 & $\mathrm{~N} / \mathrm{A}^{(1)}$ \\
SRS Total & 0.0308 & .4 \\
\hline
\end{tabular}

(1) Limit applies to the entire site release and not to each source.

\subsubsection{Worker Health Effects}

HB-Line and FWR worker exposures to radiation under normal operations would be controlled under established procedures that require doses to be kept As Low As Reasonably Achievable (ALARA) and limit any individual's dose to less than 5 rem per year. WSRC has placed further administrative limits on worker dose to $1.5 \mathrm{rem} / \mathrm{year}$ (WSRC, 1992a). Based on operations in 1993 and a maximum of 200 workers, DOE expects that the average annual dose for HB-Line facility radiation workers (operators, mechanics, health physics inspectors, support personnel etc.) from the proposed action would be less than $0.5 \mathrm{rem}$ per year. The cumulative worker dose would not exceed 100 person-rem per year (WSRC, 1993c). Under normal operation, based on an occupational risk factor of $4 \times 10^{-4}$ fatal cancers per person-rem (NRC 1991), workers engaged in the operation of HB-Line and the Frame Waste Recovery would not be expected to incur any harmful health effects from radiation exposures they receive.

Other worker health effects would be exposures to chemical hazards. There are no chemical hazards associated with cold feed preparation and storage so long as the chemicals remain within the confines of the intended vessels and piping. Unconfined, the hazards are toxicity, corrosion, fire, and carcinogenicity. 


\subsubsection{Waste Management}

Processing of $\mathrm{Pu}-238$ oxide results in the generation of low-level radioactive solid waste (LLW), transuranic (TRU) waste (including mixed TRU waste), and radioactive liquid waste. Liquid waste would be transferred to the $241-\mathrm{H}$ waste tank where it would be stored until it can be converted to borosilicate glass and saltstone. Waste generation rates for current HB-Line and FWR operations, which are expected to continue if the proposed action is implemented, are shown in Table 5-4.

DOE recently issued the Final Supplemental EIS for the Defense Waste Processing Facility (DOE, 1994a). A Record of Decision was issued on March 28, 1995, in which DOE describes the decision to complete construction and startup testing and operate the Defense Waste Processing Facility as currently designed. This decision means that liquid radioactive waste generated as a result of the proposed action described in this EA would be transferred to the 241-H waste tank for storage prior to processing in the Defense Waste Processing Facility. As shown in Table 5-4, the current inventory of liquid waste awaiting processing in the DWPF is about $34,600,000$ gallons, and continuing SRS operations (including HB-Line and FWR operations) are expected to generate an additional 5,810,000 gallons over the next 30 years (DOE, 1995). The environmental impacts of processing this liquid waste in the DWPF and associated facilities are fully described in DWPF Final Supplemental EIS (DOE, 1994a). Because the waste generated by the proposed action represents a small fraction of the total, and because the liquid waste has the same characteristics and would be managed in the same manner, the incremental environmental impacts resulting from the proposed action would be a small fraction of the impacts resulting from management of the current and forecasted SRS liquid waste inventory.

DOE recently issued the Draft EIS on Waste Management at the Savannah River Site (DOE, 1995). The Draft EIS describes alternatives for management of the current and projected inventory of waste types at the Savannah Site, including waste that would be generated as a result of the proposed action described in this EA. The EIS describes the environmental impacts of the construction and operation of the specific treatment, storage, and disposal facilities proposed in each of three management alternatives: Limited Treatment, Moderate Treatment, and Extensive Treatment. In addition, the EIS describes the impacts of managing minimum, maximum, and expected (best estimate) quantities of waste by waste type for each management alternative. Table 5-4 shows the volumes of low-level solid waste and TRU waste that would be generated by the proposed action described in this EA, and compares them to the expected inventory of the same types of waste requiring management as described in Draft Waste Management EIS. Because the waste generated by the proposed action represents a small fraction of the total, and because the low-level solid and TRU waste has the same characteristics and would be managed in the same manner, the incremental environmental impacts resulting from the proposed action would be a small fraction of the impacts resulting from management of the current and forecasted SRS lowlevel solid and TRU waste inventory. 
Table 5-4

HB-Line, FWR and Forecasted Waste Generation

\begin{tabular}{|c|c|c|c|}
\hline WASTE TYPE & $\begin{array}{l}\text { HB-Line, FWR } \\
\text { GENERATION }\end{array}$ & $\begin{array}{l}\text { Inventory and } \\
\text { Forecasted } \\
\text { Generation } \\
\end{array}$ & $\begin{array}{c}\text { Management } \\
\text { FACILITY }\end{array}$ \\
\hline Low-Level Solid[a] & $11,000 \mathrm{ft}^{3} / \mathrm{yr}$ & $51,000,000 \mathrm{ft}^{3 \mathrm{c}}$ & $\begin{array}{l}\text { Solid Waste } \\
\text { Disposal Facility }\end{array}$ \\
\hline TRU Waste ${ }^{[a]}$ & $2,000 \mathrm{ft}^{3} / \mathrm{yr}$ & $972,200 \mathrm{ft}^{3} \mathrm{c}$ & $\begin{array}{l}\text { TRU Waste Storage } \\
\text { Pad }\end{array}$ \\
\hline Liquid Waste $e^{[b]}$ & $\begin{array}{l}2,290 \mathrm{gal} / \mathrm{kg} \\
\mathrm{Pu}-238\end{array}$ & $\begin{array}{r}34,600,000 \mathrm{gal}^{\mathrm{c}} \\
5,810,000 \mathrm{gal}^{\mathrm{d}}\end{array}$ & $\begin{array}{l}\text { 241-H Waste Tank } \\
\text { DWPF, Saltstone } \\
\text { Facility }\end{array}$ \\
\hline
\end{tabular}

[a] December 1993 Facility Solid Waste Generation Report (Lambert, 1994).

${ }^{[b]}$ Frame Waste Recovery waste volume estimates (Pickett, 1991).

[c] Expected Case 30 year waste generation estimate, including Current inventory (DOE, 1995)

[d] Expected Case 30-year waste generation estimate (DOE, 1995)

\subsection{Accident Analysis}

Accident analysis methodology, assumptions, and source terms are provided in detail for the Scrap Recovery Facility (Phase I) and the Plutonium Oxide Facility (Phase III) in the Safety Analysis Report (SAR) (DuPont, 1991) and the Justification for Continued Operation (JCO) (WSRC, 1992b, WSRC, 1994a). Information in the SAR has been simplified in the discussions presented in this EA. Calculations were recently updated to provide the co-located worker, on-site population, and off-site population doses for this assessment based on the new meteorological and population databases (DelGenio, 1994a; DelGenio, 1994b). The updated analysis shows that accident consequences remain within the authorization basis outlined in the SAR and JCO. This was expected since the effects of the new meteorological and population databases on the calculated results has been previously evaluated and found generally to lower the estimated dose consequence (Huang and Hang, 1993).

Accident analysis methodology, assumptions, and source terms are provided in detail for the Frame Waste Recovery Unit in the H-Canyon SAR (DuPont, 1986) and consequences have been re-evaluated for Frame Waste Recovery with revised source terms and frequencies in Addendum 4 (WSRC, 1994b). The Addendum incorporates new source terms, meteorological and population databases, and new receptors. The evaluation considers the following accidents:

Erame Waste Recovery
$: \quad$ Earthquake
$: \quad$ Cxternally Induced Failures
$: \quad$ Firicality
- $\quad$ Uncontrolled Reaction
Transfer Error

\begin{tabular}{ll}
\multicolumn{2}{l}{ HB-Line } \\
$:$ & Earthquake \\
$:$ & Externally Induced Failures \\
- & Friticality \\
- & Uncontrolled Reaction \\
& Transfer Error
\end{tabular}




$\begin{array}{lll}- & \text { Overflow } \\ \text { Leak } & \text { Coil and Tube Failure }\end{array} \quad \begin{aligned} & \text { Overflow } \\ & \text { Leak }\end{aligned}$

Residual activity releases, although abnormal and analyzed in the SARs, are expected and do occur throughout the year. Since these are accounted for in the measured yearly releases due to normal operation these incidents are not analyzed in this section. For doses due to normal operation which include residual releases throughout the year see Section 5.1.

Accident consequence calculations do not take credit for any mitigating actions or systems such as operator response or redundant process controls. The only preventive actions or systems considered in the accident analyses are safety related systems and their automatic operation. Accident mitigation systems for which credit is taken are:

- the passive containment of the building and ventilation system structure if the ventilation system fans fail, or

- the ventilation ducts and sand filter if the canyon ventilation fans continue to operate. The accident analysis assumes the ventilation system fails completely for a point strike tomado or an earthquake.

The offsite doses and onsite population dose is calculated using 99.5 percentile meteorology using the new 1987-1991 meteorology database. The word percentile is a statistical term applied to a normal distribution of observable weather conditions. The co-located worker doses are evaluated for an individual 640 meters from the release point at 50 percentile meteorology. The distance of 640 meters from the release point is the threshold distance which differentiates an exposed person as either a co-located worker or a facility worker. A co-located worker is defined as a person who is located at a distance equal to or greater than 640 meters. The impacts to facility (involved) workers were determined through a qualitative analysis and are shown in Table 5-5. The 1994 population was estimated from 1990 census data and 1992 onsite population database. Doses provided below represent 50 year committed effective doses. Fifty year committed effective dose refers to the resultant cumulative dose up to 50 years following the exposure.

Consequences to facility workers have been evaluated on a qualitative basis (Heal et al., 1995). Facility workers are typically in close proximity to operations and are the populations principally at risk from potential consequences associated with facility hazards. Programmatic commitments, such as policies, programs, and procedures in addition to facility design features have been developed to protect facility workers. Emphasis has been placed on the integration of various regulation design codes, and programs into a Process Safety Management Program. Safety management programs ensures facility safety on a day-to-day basis through (1) adequate level of worker safety from routine industrial hazards, (2) adequate level of worker and public safety from normal operational releases and exposures, and (3) adequate level of worker and general public safety from postulated accidental releases of radioactive and chemical hazardous material.

Safety management is a abroad discipline covering several topics, from hazard identification and assessment to hazard control that are related to worker safety include criticality protection, radiation protection, hazardous material protection, training, conduct of operations, and emergency preparedness. Protection against process hazards is provided by distance, shielding and confinement barriers.

A qualitative analysis has been performed on the hazards to which facility workers are exposed. The results from this qualitative analysis are summarized along with the results from the quantitative analysis performed for the maximum off-site individual, on-site worker, the off-site population, and the on-site population. 


\subsubsection{HB-Line Facilities (Phases I and III)}

Table 5-5 summarizes the qualitative hazards to facility workers. Table 5-6 through Table 5-8 summarize the accident scenarios which result in the highest doses from the Scrap Recovery Facility and Plutonium Oxide Facility in HB-Line. The consequences provided below are for failure of both HEPA stages. A description of the events follows.

A medium energetic event is one which will cause penetration of the primary confinement barrier and bypass of the secondary barrier for a short period of time (e.g., vessel penetrated and cabinet temporarily breached). The following medium energetic events were analyzed: cabinet fire, uncontrolled reaction, and criticality. The expected frequency for a medium energetic event is the sum of the frequencies for each event. The frequencies for fire and uncontrolled reaction are based on the historical average for these events in the "old" HB-Line. Pu-238 processed in HB-Line must be within specific isotopic limits consistent with the ANSI Standards fro Special Actinide Elements subcritical limit. This limit is included in the HB-Line Operational Safety Requirements. The significant decay heat generated by $\mathrm{Pu}-238$ precludes the assembly of a critical mass of the isotope. Administrative controls are established in HB-Line on Pu-238 quantities, and the impracticality of assembling the isotope in quantity renders criticality an incredible event.

A low energetic event is one which may cause penetration of the primary confinement barrier (vessel). The following low energetic events were analyzed: process equipment leaks, transfer errors, overflows, and spills. The expected frequencies are also based on the historical average of events occurring in the "old" HB-Line and are also considered conservative when applied to the existing HB-Line facility.

A propagated fire is a fire that spreads uncontrollably throughout the facility. 
Table 5-5

Facility Worker Qualitative Hazard Evaluation

\begin{tabular}{|c|c|c|c|}
\hline Area & Hazard & Frequency & Potential Impact \\
\hline \multirow{12}{*}{$\begin{array}{l}\text { Scrap Recovery } \\
\text { Process }\end{array}$} & Small Fire & $\overline{\bar{A}}$ & Minor \\
\hline & Large Fire & $\mathrm{U}$ & Considerable injury \\
\hline & Explosion in Dissolver & A & $\begin{array}{l}\text { Considerable impact } \\
\text {-large quantity } \mathrm{Pu}- \\
238 \text { in dissolver }\end{array}$ \\
\hline & $\begin{array}{l}\text { Hydrogen Explosion in Filtrate } \\
\text { Tank }\end{array}$ & $\mathrm{U}$ & Minor \\
\hline & $\begin{array}{l}\text { Hydrogen Explosion in Product } \\
\text { Hold Tank }\end{array}$ & $\mathrm{U}$ & $\begin{array}{l}\text { Considerable impact- } \\
\text { large quantity Pu- } \\
238 \text { in hold tank }\end{array}$ \\
\hline & Air Reversal & A & Minor \\
\hline & Leaks & A & Minor \\
\hline & Dropped Container & A & Minor \\
\hline & Overflow of Process Vessel & A & $\begin{array}{l}\text { Considerable impact- } \\
\text { Moderate quantities } \\
\text { radioactive waste } \\
\text { released }\end{array}$ \\
\hline & Overflow of Chemical Hold Tank & A & Minor \\
\hline & Uncontrolled Chemical Reaction & A & Minor \\
\hline & Punctured or Damaged Glove & A & Minor \\
\hline \multirow{5}{*}{$\begin{array}{l}\text { Plutonium Oxide } \\
\text { Process }\end{array}$} & Small Fire & A & Minor \\
\hline & Large Fire & $\mathrm{U}$ & $\begin{array}{l}\text { Considerable impact- } \\
\text { up to batch quantities } \\
\mathrm{Pu}-238\end{array}$ \\
\hline & Air Reversal & A & Minor \\
\hline & Punctured or Damaged Glove & A & Minor \\
\hline & Inadvertent Criticality & I & $\begin{array}{l}\text { Considerable impact } \\
\text { or even death }\end{array}$ \\
\hline \multirow[t]{2}{*}{ Waste Handling Line } & Small Fire & A & Minor \\
\hline & Dropped Container & A & Minor \\
\hline \multirow[t]{4}{*}{ HB Line Building } & Lightning Strike to Building & A & Minor \\
\hline & Criticality in Vault . & I & $\begin{array}{l}\text { Considerable injury } \\
\text { or even death }\end{array}$ \\
\hline & Earthquake & $\mathrm{U}$ & $\begin{array}{l}\text { Considerable injury } \\
\text { or even death }\end{array}$ \\
\hline & Tornado & $\mathrm{U}$ & Minor \\
\hline \multicolumn{4}{|c|}{$\begin{array}{l}\mathrm{A}=\text { Anticipated=greater than } 1 \times 10^{-2} \text { event per year. } \\
\mathrm{U}=\text { Unlikely=between } 1 \times 10^{-2} \text { and } 1 \times 10^{-4} \text { events per year. } \\
\mathrm{I}=\mathrm{Incredible=less} \text { than } 1 \times 10^{-6} \text { events per year. }\end{array}$} \\
\hline
\end{tabular}


Table 5-6

Maximum Accident Dose Summary

Scrap Recovery Facility

\begin{tabular}{|c|c|c|c|c|}
\hline $\begin{array}{l}\text { SCRAP RECOVERY } \\
\text { Accident }\end{array}$ & $\begin{array}{l}\text { Frequency } \\
\text { (per year) }\end{array}$ & $\underset{(\mathrm{mrem} / \mathrm{yr})}{\operatorname{Risk}^{[1]}}$ & $\begin{array}{l}\text { Maximum } \\
\text { Off-site } \\
\text { Individual } \\
\text { (mrem) }\end{array}$ & $\begin{array}{c}\text { On-Site } \\
\text { Worker [2] } \\
\text { (mrem) }\end{array}$ \\
\hline $\begin{array}{l}\text { Propagated Fire } \\
\text { Medium Energetic Event } \\
\text { Earthquake } \\
\text { Low Energetic Event }\end{array}$ & $\begin{array}{c}0.0044 \\
0.0037 \\
0.00017 \\
0.21\end{array}$ & $\begin{array}{c}0.594 \\
0.0435 \\
0.00214 \\
1.23\end{array}$ & $\begin{array}{l}135 \\
11.8 \\
12.6 \\
5.87\end{array}$ & $\begin{array}{l}250 \\
21.8 \\
101 \\
10.9\end{array}$ \\
\hline
\end{tabular}

[1] Risk for the Maximum Off-Site Individual. Risk is obtained by multiplying the dose by the frequency.

[2] Dose to a worker 640 meters from the stack at 50 percentile meteorology.

Table 5.7 Maximum Accident Dose Summary
Plutonium Oxide Facility

\begin{tabular}{lcccc}
\hline \hline PLUTONIUM OXIDE & $\begin{array}{c}\text { Frequency } \\
\text { (per year) }\end{array}$ & $\begin{array}{c}\text { Risk }{ }^{11]} \\
\text { (mrem/yr) }\end{array}$ & $\begin{array}{c}\text { Maximum } \\
\text { Offsite } \\
\text { Individual } \\
\text { (mrem) }\end{array}$ & $\begin{array}{c}\text { On-Site } \\
\text { Worker }{ }^{2]} \\
\text { (mrem) }\end{array}$ \\
\hline \hline Propagated Fire & 0.0066 & 0.304 & 46.0 & 85.0 \\
Medium Energetic Event & 0.0007 & 0.00297 & 4.24 & 7.85 \\
Earthquake & 0.00017 & 0.00073 & 4.3 & 34.4 \\
Low Energetic Event & 0.06 & 0.0126 & 0.210 & 0.389 \\
\hline
\end{tabular}

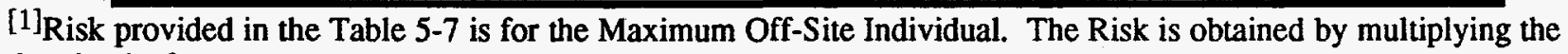
dose by the frequency.

${ }^{[2]}$ Dose to a worker 640 meters from the stack at 50 percentile meteorology. 
Table 5-8

HB-Line (Phases I and III) Maximum Accident Dose to Populations

\begin{tabular}{lcccc}
\hline \hline & \multicolumn{2}{c}{ PHASE I } & \multicolumn{2}{c}{ PHASE III } \\
& $\begin{array}{c}\text { SCRAP RECOVER } \\
\text { Off-site } \\
\text { Population }\end{array}$ & $\begin{array}{c}\text { On-site } \\
\text { Population }\end{array}$ & $\begin{array}{c}\text { PLUTONIUM OXIDE } \\
\text { Off-site } \\
\text { Population }\end{array}$ & $\begin{array}{c}\text { On-site } \\
\text { Population }\end{array}$ \\
Accident & (person-rem) & (person-rem) & (person-rem) & (person-rem) \\
\hline \hline Propagated Fire & 1,210 & 418 & 324 & 112 \\
Medium Energetic Event & 143 & 49.2 & 51.4 & 17.7 \\
Earthquake & 77.4 & 46.3 & 20.7 & 12.4 \\
Low Energetic Event & 71.1 & 24.5 & 2.55 & 0.879 \\
\hline
\end{tabular}

\subsubsection{Frame Waste Recovery (FWR)}

Table 5-9 summarizes the hazardards to workers from Frame Waste Recovery process operation. Presented in Tables 5-10 and Table 5-11 is a summary of the maximum doses resulting from accident scenarios in the FWR Unit. The maximum consequences are derived from maximum source terms and are therefore considered bounding in estimating off-site dose. Since the frequencies and the release values are calculated means, it is inappropriate to apply these mean frequencies to maximum consequences. However, although not a realistic estimate, the mean frequencies are a conservative estimate for defining the beginning of the frequency range for a given accident. The frequencies for a Maximum Fire and Maximum Transfer Error were analyzed more closely and more appropriate frequencies were calculated (WSRC, 1994b).

\section{Table 5-9}

Facility Worker Qualitative Hazard Evaluation

\begin{tabular}{llll}
\hline \multicolumn{1}{c}{ Area } & \multicolumn{1}{c}{ Hazard } & Frequency & Potential Impact \\
\hline \hline $\begin{array}{l}\text { Frame Waste } \\
\text { Recovery }\end{array}$ & $\begin{array}{l}\text { Puncture wound from } \\
\text { sample needle }\end{array}$ & A & $\begin{array}{l}\text { Considerable injury or } \\
\text { even death }\end{array}$ \\
& $\begin{array}{l}\text { Sample vial of } \\
\text { radioactive material is } \\
\text { dropped }\end{array}$ & $\begin{array}{l}\text { Considerable impact to } \\
\text { facility worker }\end{array}$ \\
& $\begin{array}{l}\text { Failure to apply } \\
\text { process air after } \\
\text { completion of a } \\
\text { solution transfer }\end{array}$ & A & $\begin{array}{l}\text { Considerable impact to } \\
\text { facility worker }\end{array}$ \\
\hline
\end{tabular}

$\mathrm{A}=$ Anticipated $=$ greater than $1 \times 10^{-2}$ event per year 
Table 5-10

\section{Maximum Accident Dose Summary Frame Waste Recovery Facility}

\begin{tabular}{llccc}
\hline \hline Accident & $\begin{array}{c}\text { Frequency } \\
\text { (per year) }\end{array}$ & $\begin{array}{c}\text { Risk } \\
\text { (mrem/yr) }\end{array}$ & $\begin{array}{c}\text { Maximum } \\
\text { Offsite } \\
\text { Individual } \\
\text { (mrem) }\end{array}$ & $\begin{array}{c}\text { On-Site } \\
\text { Worker[2] } \\
\text { (mrem) }\end{array}$ \\
\hline \hline Earthquake & 0.000200 & 0.220 & 1,100 & 1,090 \\
External Impact & $\leq 0.00876$ & $\leq 0.141$ & 16.0 & 29.8 \\
Fire & $\leq 0.0000211$ & $\leq 0.00639$ & 303 & 562 \\
Uncontrolled Reaction & $\leq 0.0790$ & $\leq 2.5$ & 31.6 & 58.6 \\
Transfer Error to Sump & $\leq 0.0810$ & $\leq 1.3$ & 16.0 & 29.8 \\
Transfer Error to Outside & $\leq 0.000404$ & $\leq 0.271$ & 672 & 1,250 \\
Overflow & $\leq 0.248$ & $\leq 3.97$ & 16.0 & 29.8 \\
Leak & $\leq 0.576$ & $\leq 7.83$ & 13.6 & 25.1 \\
Coil \& Tube Failure & $\leq 0.0150$ & $\leq 4.35$ & 290 & N/A $[2]$ \\
\hline
\end{tabular}

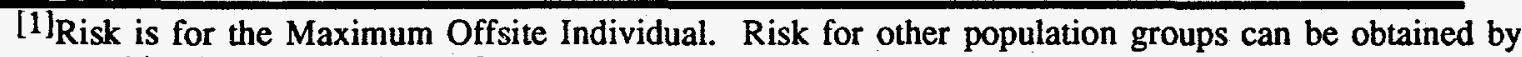
multiplying the dose by the frequency.

${ }^{[2]}$ There are no on-site receptors for this release pathway.

Table 5-11

Frame Waste Recovery Process Maximum Accident Dose to Populations

\begin{tabular}{llcc}
\hline Accident & $\begin{array}{c}\text { Frequency } \\
\text { (per year) }\end{array}$ & $\begin{array}{c}\text { Off-site Population } \\
\text { (person-rem) }\end{array}$ & $\begin{array}{c}\text { On-site Population } \\
\text { (person-rem) }\end{array}$ \\
\hline \hline Earthquake & 0.000200 & 9,030 & 5,490 \\
External Impact & $\leq 0.00876$ & 192 & 67.5 \\
Fire & $\leq 0.0000211$ & 3,630 & 1,270 \\
Uncontrolled Reaction & $\leq 0.0790$ & 31.6 & 133 \\
Transfer Error to. Sump & $\leq 0.0810$ & 192 & 67.5 \\
Transfer Error to Outside & $\leq 0.000404$ & 8,050 & 2,820 \\
Overflow & $\leq 0.248$ & 192 & 67.5 \\
Leak & $\leq 0.576$ & 162 & 57.0 \\
Coil \& Tube Failure & $\leq 0.0150$ & 7,600 & N/All] \\
\hline
\end{tabular}

[1]There are no on-site receptors for this release pathway.

The maximum dose in operating the Frame Waste Recovery Facility occurs in the event of a $0.2 \mathrm{~g}$ earthquake. This is an extremely low probability event, and therefore the risk (dose times frequency) is less than that for higher frequency, lower dose events.

\subsubsection{Onsite (SRS) Transportation Accidents}

Consequences and risks to the off-site public and on-site population from potential accidents during on-site transportation of radioactive materials have been analyzed in Safety Analysis - 
Evaluation of Accident Risks in the Transportation of Hazardous Materials by Truck and Rail at the Savannah River Site (WSRC, 1989d). The accident with the highest risk and the highest dose was found to be a breach or puncture of a transuranic waste drum. The most frequent accident was calculated to be an accidental release to the atmosphere from a low level waste trailer. The doses and frequencies are summarized in Table 5-12.

Table 5-12

Onsite Transportation Accident Summary

\begin{tabular}{ccccc}
\hline \hline Accident & $\begin{array}{c}\text { Frequency } \\
\text { (per year) }\end{array}$ & $\begin{array}{c}\text { Maximum } \\
\text { Offsite } \\
\text { Individual } \\
\text { (mrem) }\end{array}$ & $\begin{array}{c}\text { Offsite } \\
\text { Population } \\
\text { (person-rem) }\end{array}$ & $\begin{array}{c}\text { Onsite } \\
\text { Population } \\
\text { (person-rem) }\end{array}$ \\
\hline $\begin{array}{c}\text { Breach of TRU Drum } \\
\text { (highest consequence) }\end{array}$ & 0.00003 & 19 & 130 & 27 \\
$\begin{array}{c}\text { Low Level Waste Trailer } \\
\text { Atmospheric Release } \\
\text { (most frequent) }\end{array}$ & 0.10 & 0.000089 & 0.00030 & 0.000051 \\
\hline
\end{tabular}

\subsubsection{Incident-Free Off-site Transportation}

DOE analyzed both incident-free and accident radiological impacts for the shipping of plutonium scrap. Routing conditions (including population densities, distance and time traveled, and fraction of travel in different population zone types (rural, suburban, and urban)) were obtained from the HIGHWAY computer code (Johnson et. al. 1993). Concentrations of identified isotopes were calculated based on an assumed isotopic distribution (Jacobson 1994c). Shipping package radioactivity and SST loading were based on safety analysis information supplied for each package type. Gamma dose rates from each shipping package were derived similarly (HNUS 1994). Routing demographics, dose rates, and neutron-gamma fractions were used as input to the computer code RADTRAN 4 (Neuhauser 1992) to obtain radiological impacts.

The magnitude of incident-free radiation exposure depends on the dose rate on the external surface of the transport vehicle, the exposure time and distance, and the number of people exposed. During incident-free transport, external radiation exposure would occur to the transportation workers (loading and unloading crews and transport vehicle crew), persons sharing the transportation link at the time of shipment (escort vehicles and general public), and persons near the transportation link as the shipment passes. Table 5-13 provides the results of the incident-free analysis for shipping the plutonium scrap from Mound and LANL to SRS for both package types and full and half-load SST capacities. Maximum and typical packaging configurations were analyzed. The maximum exposed individual (MEI) is located by RADTRAN at 30 meters from the road. 
Table 5-13

Incident-Free Transportation Impacts for Shipments to SRS

\begin{tabular}{|c|c|c|c|c|c|c|c|}
\hline $\begin{array}{l}\text { Origin / } \\
\text { Pkg Type }\end{array}$ & $\begin{array}{l}\text { Load } \\
\text { Type }\end{array}$ & $\begin{array}{l}\text { grams / } \\
\text { package }\end{array}$ & $\begin{array}{l}\text { Ship- } \\
\text { ments }\end{array}$ & $\begin{array}{l}\text { Public Dose } \\
\text { (person-rem) }\end{array}$ & $\begin{array}{l}\mathrm{MEI}^{*} \\
\text { (rem) }\end{array}$ & $\begin{array}{l}\text { Handler Dose } \\
\text { (person-rem) }\end{array}$ & $\begin{array}{l}\text { Crew Dose } \\
\text { (person-rem) }\end{array}$ \\
\hline Mound & Full & 196 & 3 & $5.19 \mathrm{E}-02$ & $1.91 \mathrm{E}-07$ & $3.04 E+00$ & $2.17 \mathrm{E}-01$ \\
\hline \multirow[t]{6}{*}{$(10$} & Half & 196: & 6 & $5.00 \mathrm{E}-02$ & $9.20 \mathrm{E}-08$ & $2.03 E+00$ & $2.18 \mathrm{E}-01$ \\
\hline & Full & 160 & 4 & $4.94 \mathrm{E}-02$ & $1.56 \mathrm{E}-07$ & $2.89 \mathrm{E}+00$ & $2.06 \mathrm{E}-01$ \\
\hline & Half & 160 & 7 & $4.76 \mathrm{E}-02$ & $7.51 \mathrm{E}-08$ & $2.48 \mathrm{E}+00$ & $2.08 E-01$ \\
\hline & Full & 884 & 3 & $1.02 \mathrm{E}-01$ & $3.75 \mathrm{E}-07$ & 8.41E-01 & $2.49 \mathrm{E}-01$ \\
\hline & Half & 884. & 6 & 1.31E-01 & $2.42 \mathrm{E}-07$ & $8.21 E-01$ & $3.84 \mathrm{E}-01$ \\
\hline & Full & 720 & 4 & $1.10 \mathrm{E}-01$ & $3.05 \mathrm{E}-07$ & 8.00E-01 & $2.37 \mathrm{E}-01$ \\
\hline $1 \mathrm{~kW}$ & Half & 720 & 7 & $1.25 \mathrm{E}-01$ & $1.97 \mathrm{E}-07$ & $7.80 \mathrm{E}-01$ & $3.64 \mathrm{E}-01$ \\
\hline & Full & 196 & 10 & $2.59 \mathrm{E}-01$ & $1.91 \mathrm{E}-07$ & $1.01 E+01$ & $1.81 E+00$ \\
\hline$(35 \mathrm{~kg})$ & Half & 196 & 20 & $2.50 \mathrm{E}-01$ & $9.20 \mathrm{E}-08$ & $6.70 \mathrm{E}+00$ & $1.82 E+00$ \\
\hline 5320 & Full & 160 & 12 & $2.53 \mathrm{E}-01$ & $1.56 \mathrm{E}-07$ & $9.92 E+00$ & $1.77 E+00$ \\
\hline & Half & 160 & 24 & $2.44 \mathrm{E}-01$ & $7.51 \mathrm{E}-08$ & $6.61 E+00$ & $1.79 \mathrm{E}+00$ \\
\hline \multirow[t]{4}{*}{$1 \mathrm{~kW}$} & Full & 884 & 10 & $5.20 \mathrm{E}-01$ & $3.75 \mathrm{E}-07$ & $2.80 \mathrm{E}+00$ & $2.08 \mathrm{E}+00$ \\
\hline & Half & 884 & 20 & $6.72 \mathrm{E}-01$ & $2.42 \mathrm{E}-07$ & $2.74 \mathrm{E}+\infty 0$ & $3.22 \mathrm{E}+00$ \\
\hline & Full & 720 & 12 & $5.08 \mathrm{E}-01$ & $3.05 \mathrm{E}-07$ & $2.74 E+\infty 0$ & $2.04 \mathrm{E}+00$ \\
\hline & Half & 720 & 24 & $6.57 \mathrm{E}-01$ & $1.97 \mathrm{E}-07$ & $2.67 \mathrm{E}+00$ & $3.13 E+00$ \\
\hline
\end{tabular}

1 MEI values indicate the probability of a latent cancer fatality

\subsubsection{Transportation Accidents}

Radiological consequences from an accident due to transport vehicle collision would result primarily from release of respirable radioactive particulates and subsequent inhalation by individuals downwind of the accident, either directly or after re suspension. Other exposure pathways would include direct radiation from the cloud of airborne material and from contamination on the ground.

The magnitude of accident consequence depends on the amount of radioactive material the individual(s) are exposed to, the exposure time, and the number of people exposed. NUREG0170 (USNRC 1977) provides criteria for determining the magnitude and probability of a given severity of an accident based on impact and thermal forces the transport vehicle and its contents could be exposed to. It would be necessary for an SST to be exposed to the most severe accident (the lowest probability of all accident types) conditions (Category VIII) to release any material by breaching shipping packages. The highest probability of any accident occurring would be for a Category I accident; however, no radioactive material would be released due to the low impact to the package. For any accident other than a Category VIII there would be no release of material and consequences would be similar to the incident-free conditions previously described. Accident probability for a Category VIII accident was adapted from NUREG-0170 (HNUS 1994) and found to be less than $4 \times 10^{-10}$ (less than 4 chances in a trillion). Because possibility of such an accident is so remote, the consequences have not been analyzed further.

\subsubsection{Nonradiological Transportation Accidents}


The nonfatal and fatal accident probabilities per shipment for material transport along the longest route postulated in the analysis are calculated to be $2.0 \mathrm{E}-3$ and $1.5 \mathrm{E}-4$, respectively. The average nonfatal accident rate for vehicles such as SSTs is 4.6E-7 accidents per kilometer (USNRC 1977). The traffic fatality rate used in the analysis is from Department of Transportation (DOT 1989) data for the commercial shipping industry for trucks and is based on millions of total vehicle-kilometers of travel. DOE assumes that the percent of accidents resulting in a fatality would be the same as that for interstate travel by truck (7.5 percent) (DOT 1989). Therefore, the traffic fatality rates in the analysis are conservatively assumed to be equal to the national average for commercial shipping.

\subsubsection{Health Effects}

Health effects measured as the number of latent cancer fatalities (LCFs) were calculated by multiplying the resultant worker and general public consequences by the risk factors of $4 \mathrm{E}-4$ and 5E-4 LCFs per person-rem (DOE 1993b), respectively. For individual exposures, these same values are used to calculate cancer mortality probability.

Table 5-14 presents the calculated total incidence and maximum probability of LCFs for incidentfree shipments to SRS.

\subsection{Effects of Radiological Doses}

In this analysis the major impact from operation of these facilities under both normal and accident conditions is exposure to radiation or radiation dose. The following discussion is provided to aid in understanding the effects of these doses. 
Table 5-14

Number and Probability of Latent Cancer Fatalities for Incident-Free Transportation to SRS

\begin{tabular}{|c|c|c|c|c|c|c|}
\hline $\begin{array}{l}\text { Origin I } \\
\text { Pkg Type }\end{array}$ & $\begin{array}{l}\text { Load } \\
\text { Type }\end{array}$ & $\begin{array}{l}\text { grams / } \\
\text { package }\end{array}$ & $\begin{array}{l}\text { Ship- } \\
\text { ments }\end{array}$ & $\begin{array}{l}\text { Public } \\
\text { LCFs }\end{array}$ & $\begin{array}{l}\text { MEI }^{1} \\
\text { LCFs }^{2}\end{array}$ & $\begin{array}{l}\text { Worker } \\
\text { LCFs }\end{array}$ \\
\hline Mound & Full & 196 & 3 & $3 E-05$ & $1 \mathrm{E}-10$ & $1 E-03$ \\
\hline$(10 \mathrm{~kg})$ & Half & 196 & 6 & $3 E-05$ & $5 \mathrm{E}-11$ & 9E-04 \\
\hline \multirow[t]{2}{*}{5320} & Full & 160 & 4 & 2E-05 & $8 \mathrm{E}-11$ & 1E-03 \\
\hline & Half & 160 & 7 & $2 E-05$ & $4 \mathrm{E}-11$ & $1 E-03$ \\
\hline \multirow[t]{4}{*}{$1 \mathrm{~kW}$} & Full & 884 & 3 & $5 E-05$ & $2 \mathrm{E}-10$ & 4E-04 \\
\hline & Half & 884 & 6 & $7 \mathrm{E}-05$ & $1 E-10$ & $5 E-04$ \\
\hline & Full & 720 & 4 & $6 \mathrm{E}-05$ & $2 E-10$ & $4 \mathrm{E}-04$ \\
\hline & Half & 720 & 7 & $6 \mathrm{E}-05$ & $1 E-10$ & 5E-04 \\
\hline & Full & 196 & 10 & 1E-04 & $1 \mathrm{E}-10$ & $5 E-03$ \\
\hline$(35 \mathrm{~kg})$ & Half & 196 & 20 & 1E-04 & SE-11 & $3 E-03$ \\
\hline \multirow[t]{2}{*}{5320} & Full & 160 & 12 & $1 E-04$ & $8 E-11$ & 5E-03 \\
\hline & Half & 160 & 24 & $1 E-04$ & $4 \mathrm{E}-11$ & $3 E-03$ \\
\hline \multirow[t]{4}{*}{$1 \mathrm{~kW}$} & Full & 884 & 10 & $3 E-04$ & $2 E-10$ & $2 \mathrm{E}-03$ \\
\hline & Half & 884 & 20 & $3 E-04$ & $1 \mathrm{E}-10$ & $2 E-03$ \\
\hline & Full & 720 & 12 & $3 E-04$ & $2 \mathrm{E}-10$ & $2 \mathrm{E}-03$ \\
\hline & Half & 720 & 24 & $3 E-04$ & $1 \mathrm{E}-10$ & $2 \mathrm{E}-03$ \\
\hline
\end{tabular}

${ }^{1}$ MEI values indicate the probability of a latent cancer fatality

\subsubsection{Collective Doses}

Because there is much uncertainty concerning the effects of radiation at low doses and dose rates, scientists conservatively use a linear model to extrapolate the cancer risks known from higher doses and dose rates. The conversion factor for excess cancer mortality in the general population from radiation exposure is $5.0 \times 10^{-4}$ Latent Cancer Fatalities (LCFs) per person-rem and for workers is $4.0 \times 10^{-4}$ LCFs per person-rem (NRC, 1991). The difference in risk factors is attributable to the presence of children in the general population. Table 5-15 provides the predicted number of LCFs for the doses in this analysis.

\subsubsection{Individual Doses}

Because the probability of cancer in a specific individual cannot be predicted, the probability of latent fatal cancer for specific individuals was not calculated. Effects of individual radiation doses are best interpreted by comparing them to similar levels encountered in daily life and to regulatory limits. The following facts are provided as a frame of reference to compare the individual doses provided in this analysis.

- The average annual dose from natural sources (radon, terrestrial radiation, cosmic radiation, and from ingested natural radioisotopes, especially potassium-40) to an individual living in the SRS area is about $315 \mathrm{mrem}$ (WSRC, 1993a). 
- In 1993, the dose to the maximally exposed offsite individual from SRS operations was 0.27 mrem (WSRC, 1993a).

- The DOE annual limits on dose to the member of the public receiving the maximum exposure are 100 mrem from all pathways, 10 mrem from the airborne pathway, and 4 mrem from the drinking water pathway (DOE, 1990b).

- The DOE annual dose limit for a radiation worker is 5,000 mrem; SRS further restricts this limit to 1,500 mrem (DOE Order 5480.11; WSRC, 1992a).

Table 5-15

Predicted Number of Latent Cancer Fatalities

\begin{tabular}{|c|c|c|c|c|}
\hline Description & $\begin{array}{c}\text { Population } \\
\text { Exposed }\end{array}$ & $\begin{array}{c}\text { Collective } \\
\text { Dose } \\
\text { (person-rem) } \\
\end{array}$ & $\begin{array}{c}\text { Risk Factor } \\
\text { (LCFs per } \\
\text { person-rem) } \\
\end{array}$ & $\begin{array}{c}\text { Potential } \\
\text { Number of } \\
\text { LCFs }\end{array}$ \\
\hline $\begin{array}{l}\text { Normal Operation (per year) } \\
\text { (Section 5.1.5) }\end{array}$ & $\begin{array}{l}\text { Radiation } \\
\text { Workers }\end{array}$ & 100 & $4.0 \times 10^{-4}$ & 0.04 \\
\hline $\begin{array}{l}\text { Earthquake } \\
\text { (Table 5-11) }\end{array}$ & $\begin{array}{l}\text { On-site } \\
\text { Off-site }\end{array}$ & $\begin{array}{l}5490 \\
9030\end{array}$ & $\begin{array}{l}4.0 \times 10^{-4} \\
5.0 \times 10^{-4}\end{array}$ & $\begin{array}{l}2 \\
5\end{array}$ \\
\hline $\begin{array}{l}\text { Propagated Fire } \\
\text { (Table 5-8) }\end{array}$ & $\begin{array}{l}\text { On-site } \\
\text { Off-site }\end{array}$ & $\begin{array}{c}418 \\
1210\end{array}$ & $\begin{array}{l}4.0 \times 10^{-4} \\
5.0 \times 10^{-4}\end{array}$ & $\begin{array}{l}0.2 \\
0.6\end{array}$ \\
\hline $\begin{array}{l}\text { Coil \& Tube Failure } \\
\text { (Table 5-11) }\end{array}$ & $\begin{array}{l}\text { On-site } \\
\text { Off-site }\end{array}$ & $\begin{array}{c}\text { N/A[1] } \\
7600\end{array}$ & $\begin{array}{l}4.0 \times 10^{-4} \\
5.0 \times 10^{-4}\end{array}$ & $\begin{array}{l}\text { N/A } \\
4\end{array}$ \\
\hline $\begin{array}{l}\text { Bounding Onsite } \\
\text { Transportation Accident } \\
\text { (Table 5-12) }\end{array}$ & $\begin{array}{l}\text { On-site } \\
\text { Off-site }\end{array}$ & $\begin{array}{c}27 \\
130\end{array}$ & $\begin{array}{l}4.0 \times 10^{-4} \\
5.0 \times 10^{-4}\end{array}$ & $\begin{array}{l}0.01 \\
0.07\end{array}$ \\
\hline $\begin{array}{l}\text { Offsite Transportation } \\
\text { (Table 5-13) }\end{array}$ & $\begin{array}{l}\text { Public } \\
\text { Workers }\end{array}$ & $\begin{array}{c}0.657 \\
11.7\end{array}$ & $\begin{array}{l}5.0 \times 10^{-4} \\
4.0 \times 10^{-4}\end{array}$ & $\begin{array}{l}0.0003 \\
0.005\end{array}$ \\
\hline
\end{tabular}

[1] There are no receptors for this release pathway.

\subsection{REGULATORY CONSIDERATIONS}

DOE policy is to perform its operations in compliance with all existing applicable federal, state, and local laws and regulations, and with all DOE orders. This section discusses the major regulatory permit programs that might be applicable to the proposed action.

\subsection{National Environmental Policy Act of 1969}

NEPA, as amended (42 USC 4321 et seq.), requires "all agencies of the Federal Government" to prepare a detailed statement on the environmental effects of proposed "major federal actions significantly affecting the quality of the human environment." In compliance with the National Environmental Policy Act (NEPA), the requirements of the Council on Environmental Quality (40 
CFR 1500-1508), DOE Regulations 10 CFR 1021, and DOE Order 5440.1E, this Environmental Assessment (EA) addresses the potential environmental consequences of continued operation of HB-Line and Frame Waste Recovery at the Savannah River Site (SRS) to aid in determining whether a detailed environmental impact statement should be prepared.

\subsection{Solid Waste Regulations}

Miscellaneous non-radioactive, non-hazardous trash from routine operations (e.g., office waste paper, maintenance shop waste) would be disposed in the SRS Solid Waste Landfill.

Any radioactive solid waste that would be generated would be subject to the requirements of DOE Order 5820.2, "Radioactive Waste Management".

Disposal of any hazardous or mixed-wastes would be subject to the additional requirements of the Resource Conservation and Recovery Act (RCRA) and the South Carolina Hazardous Waste Management Regulations (SCHWMR) R.61-79.

\subsection{Air Emissions Regulations}

The air emissions from the $291-\mathrm{H}$ stack are currently permitted by the SCDHEC. Pursuant to regulation 40 CFR 61 of the National Emissions Standards for Hazardous Air Pollutants (NESHAP), this stack requires continuous isokinetic monitoring. Per a Federal Facilities Compliance Agreement (FFCA) between the Environmental Protection Agency, Region IV (EPAIV) and DOE-SR, effective October 31, 1991, the 291-H stack emissions monitoring system was upgraded to include isokinetic sampling in April 1993.

\subsection{Liquid Discharge Regulations}

Liquids discharged from 221-H Building are subject to the provisions of the Clean Water Act of 1977 as amended by the Water Quality Control Act of 1987 (P. L. 100-4) and the South Carolina Pollution Control Act (S.C. Code of Laws, 1976, Title 48, Chapter 1). HB-Line and Frame Waste Recovery are currently permitted under the SRS NPDES permit SC0000175.

\subsection{Transportation Regulations}

Routine activities for operation of HB-Line would involve transportation of Plutonium-238 to and from the Savannah River Site. Such transportation would be in accordance with Department of Transportation (DOT) regulations (49 CFR 171-179) and DOE Orders. In addition, applicable requirements of the Nuclear Regulatory Commission (10 CFR Part 71) would be followed and State transportation requirements applicable to transportation of radioactive material (e.g., routing requirements) would be followed to the extent that such requirements are not inconsistent with federal regulations.

\subsection{PERSONS AND AGENCIES CONSULTED}

DOE cosulted the National Aeronautics and Space Administration and Mr. Brian Costner of the Energy Research Foundation, Columbia, South Carolina, during preparation of this EA. 


\subsection{REFERENCES}

Brolin, E. C., 1993. Letter from E. C. Brolin, June 14, 1993 Acting Director, Office of Nuclear Energy, Department of Energy, to W. T. Huntress, Jr., Associate Administrator for Space Science, National Aeronautics and Space Administration.

DelGenio, M: E., 1994. Update of HB-Line Consequences Based on New Meteorological and Population Databases in AXAIR89Q, WSRC-RP-94-250, Westinghouse Savannah River Company, Savannah River Site, Aiken, S.C.

DelGenio, M. E., 1994b. Response to ESH\&QA Comments on the HB-Line JCO Rev. 1 (U), EPD-CAT-94-0040, Westinghouse Savannah River Company, Savannah River Site, Aiken, SC.

DOE (U.S. Department of Energy), 1982. Final Environmental Impact Statement, Defense Waste Processing Facility, Savannah River Plant, Aiken, South Carolina, DOE/EIS-0082, Washington, D. C.

DOE (U.S. Department of Energy), 1990a. Final Environmental Impact Statement, Continued Operation of K-, L- and P-Reactors, Savannah River Site, DOE/EIS-0147, Savannah River Operations Office, Aiken, S.C.

DOE (U.S. Department of Energy), 1990b. DOE Order 5400.5, Radiation Protection of the Public and the Environment, U. S. Department of Energy, Washington, DC.

DOE (U.S. Department of Energy), 1991. Environmental Assessment for Radioisotopic Heat Source Fuel Reprocessing and Fabrication, DOE/EA-0534, U.S. Department of Energy, Offices of Special Applications, Washington, D. C.

DOE (U.S. Department of Energy), 1993a. Environmental Assessment of the Import of Russian Plutonium-238, DOE/EA-0841, U.S. Department of Energy, Office of Nuclear Energy, Washington, D. C.

DOE (U.S. Department of Energy), 1993b. DOE NEWS Fact Sheet - Transporting and Safeguarding Special Nuclear Material, U.S. Department of Energy, Transportation Safeguards Division, Albuquerque, New Mexico.

DOE (U.S. Department of Energy), 1993c. "Recommendations for the Preparation of Environmental Assessments and Environmental Impact Statements", Office of NEPA Oversight (EH-25) U. S. Department of Energy, Washington, D.C.

DOE (U.S. Department of Energy), 1994. Final Supplemental Environmental Impact Statement, Defense Waste Processing Facility, DOE/EIS-0082, Savannah River Operations Office, Aiken, South Carolina.

DOE (U.S. Department of Energy), 1995. Draft Environmental Impact Statement, Waste Management, DOE/EIS-0217D, Savannah River Site, Aiken, South Carolina.

DOT (U.S. Department of Transportation), 1989. Accidents Reported by Motor Carriers of Property 1989, FHWA/MC-92/018, U.S. Department of Transportation, Federal Highway Administration, Office of Motor Carriers, Washington, D.C.

DuPont (E.I. du Pont Nemours \& Co.), 1986. Safety Analysis - 200 Area Savannah River Plant, H-Canyon Operations, DPSTSA-200-10-2-SUPP 5, Savannah River Plant, Aiken, S.C. 
DuPont (E.I. du Pont Nemours \& Co.), 1991. Safety Analysis - 200 Area, Separations Area Operations, Building 221-H, B-Line, Scrap Recovery Facility and Plutonium Oxide Facility, Rev. 1, DPSTSA-200-10-2, Savannah River Plant, Aiken, S.C.

HNUS (Halliburton NUS Corporation), 1994. Transportation Radiological Analysis Savannah River Site Pu-238 Processing Environmental Assessment, Aiken, South Carolina.

Heal, D,W., Paik, I.K., and Swenson, G.R., 1995. HB-Line and H-Canyon Worker Safety (U), WSRC-TR-95-0095, Rev. 0, Westinghouse Savannah River Company,Savannah River Site, Aiken, S.C.

Huang, J. C. and P. Hang, 1993. Impact of the New (1987-1991) SRS Meteorological Database on AXAIR89Q Dose Calculations (U), WSRC-RP-93-551, Westinghouse Savannah River Company,Savannah River Site, Aiken, S.C.

Huntress, W. T., Jr., 1993. Letter from W. T. Huntress, Jr., Associate Administrator for Space Science, National Aeronautics and Space Administration, to E. C. Brolin, Assistant Secretary for Nuclear Energy (Acting), Department of Energy, April 28.

Jacobson, R. Y., 1994a. Westinghouse Savannah River Company, Transportation Data Request, Interoffice memorandum to R. J. Smith, Halliburton NUS Corporation, Aiken, South Carolina, July 7.

Jacobson, R. Y., 1994b. Westinghouse Savannah River Company, HB-Line EA Information (U), Interoffice memorandum to S.W. McAlhany, U.S. Department of Energy, Aiken, South Carolina, June 20.

Jacobson, R. Y., 1994c. Westinghouse Savannah River Company, HB-Line EA Data Request (U), Interoffice memorandum to R. J. Smith, Halliburton NUS Corporation, Aiken, South Carolina, June 9.

Johnson, P. E., D. S. Joy, D. B. Clarke, and J. M. Jacobi, 1993. Highway 3.1 - An Enhanced Highway Routing Model: Program Description, Methodology, and Revised User's Manual, ORNL/TM-12124, U.S. Department of Energy, Washington, D. C.

Lambert, D. S., 1994. December 1993 - Facility Solid Waste Generation Report, WER-SWD-940021, Westinghouse Savannah River Company, Aiken, S.C.

Neuhauser, K. S. and F. L. Kanipe, 1992. RADTRAN 4: Volume 3 User Guide, SAND89-2370; TTC-0943; UC-722, Sandia National Laboratories, Albuquerque, New Mexico.

NRC (U. S. Nuclear Regulatory Commission), 1991. Preamble to Standards for Protection Against Radiation, 56 FR 23363, Nuclear Regulatory Commission, Washington, DC.

NUS (Halliburton NUS), 1992. Socioeconomic Characteristics of Selected Counties and Communities Adjacent to the Savannah River Site, Halliburton NUS, Aiken, S.C. 
Pickett, C. E., 1991. Predicted Waste Volume and Composition from Pu-238 Scrap Recovery Operations, NMP-STH-910213, Westinghouse Savannah River Company, Aiken, S.C.

USNRC (U.S. Nuclear Regulatory Commission), 1977. Final Environmental Impact Statement on the Transportation of Radioactive Material by Air and Other Modes, NUREG-0170, U.S. Nuclear Regulatory Commission, Washington, D.C.

WSRC (Westinghouse Savannah River Company), 1989a. Reactor Operation Environmental Information Document, Volume I, Geology, Seismology, Subsurface Hydrology, WSRC-RP-89-815, Savannah River Site, Aiken, S.C.

WSRC (Westinghouse Savannah River Company), 1989b. Reactor Operation Environmental Information Document, Volume II, Ecology, WSRC-RP-89816, Savannah River. Site, Aiken, S.C.

WSRC (Westinghouse Savannah River Company), 1989c. Reactor Operation Environmental Information Document, Volume III, Meteorology, Surface Hydrology (Transport Impacts), WSRC-RP-89-817, Savannah River Site, Aiken, S.C.

WSRC (Westinghouse Savannah River Company), 1989d. Safety Analysis - Evaluation of Accident Risks in the Transportation of Hazardous Materials by Truck and Rail at the Savannah River Site, WSRC-RP-89-715, Savannah River Site, Aiken, S.C.

WSRC (Westinghouse Savannah River Company), 1992a. Radiological Control, Manual 5Q, Savannah River Site, Aiken, S.C.

WSRC (Westinghouse Savannah River Company), 1992b. Savannah River Site Scrap Recovery Facility, Plutonium Oxide Facility Justification for Continued Operation, WSRC-RP-92-981, Savannah River Site, Aiken, S.C.

WSRC (Westinghouse Savannah River Company), 1993a. Savannah River Site Environmental Report for 1992, WSTRC-TR-93-075, Savannah River Site, Aiken, S.C.

WSRC (Westinghouse Savannah River Company), 1993b. December 1993 Radioactive Releases Report, ESH-EMS-93-0128, Savannah River Site, Aiken, S.C.

WSRC (Westinghouse Savannah River Company), 1993c. Nuclear Materials Processing Division Separations H-Area Facilities ALARA Performance Indicators Program, Savannah River Site, Aiken, S.C.

WSRC (Westinghouse Savannah River Company), 1994a. Savannah River Site Scrap Recovery Facility, Plutonium Oxide Facility Justification for Continued Operation, WSRC-RP-92-981, Revision 1, Savannah River Site, Aiken, SC.

WSRC (Westinghouse Savannah River Company), 1994b. H-Canyon SAR Addendum for Frame Waste Recovery, DPSTSA-200-10 SUPP-5, Addendum 4, Savannah River Site, Aiken, S.C. 


\section{APPENDIX A: COMMENTS RECEIVED ON THE DRAFT HB-LINE}

ENVIRONMENTAL ASSESSMENT, AND DOE RESPONSES

\subsection{COMMENTS TRANSMITTED TO DOE FROM THE ENERGY RESEARCH FOUNDATION (ERF), DECEMBER 8, 1994}

\subsection{ERF Comment 1}

An important point in our case for a new EA was that the purpose and need had changed significantly since 1991, and in the settlement agreement, DOE explicitly agreed to consider the need for future $\mathrm{Pu}-238$ reprocessing at SRS. It is important that this discussion of need be complete, accurate, and based on timely information.

During Mondays conference call, we raised several concerns regarding the draft EA's explanation for the need for future $\mathrm{Pu}-238$ operations. For example, the draft EA refers to "terrestrial missions" ( $p .4$ ) without offering any indication of what these missions might be. Our understanding from the call is that this phrase may simply be remaining from an earlier draft and that no such missions are planned. The revised EA should explain this point, documenting the current status of all missions for which $\mathrm{Pu}-238$ might be needed and whether in fact there are terrestrial requirements for $\mathrm{Pu}-238$.

For another example, Table 2-1 lists estimated NASA mission requirements for Pu-238. The draft EA does not, however, specify which of these missions is funded, the state of planning for each mission, or other factors which would document the actual need for additional quantities of $\mathrm{Pu}$ 238. The final EA should provide enough information so that the reader can evaluate the credibility of claimed $\mathrm{Pu}-238$ requirements.

Also, the EA should better describe the inventory of weapons return $\mathrm{Pu}-238$ and any plans for its reprocessing. The draft refers to two February 1994 memos as evidence that there are no current plans to process this material (pp. 2 \& 3) The revised EA should contain more timely information; including a declassified inventory of weapons return $\mathrm{Pu}-238$.

\subsubsection{DOE Response}

This comments raises several concerns involving the purpose and need to process Pu-238 at SRS. A response has been provided for each concern identified.

Concern \#1: The EA fails to discuss the purpose and need to processing $\mathrm{Pu}-238$ to support terrestrial missions.

Response \#1: The EA has been revised to delete "terrestrial missions" from section 1.0, "Summary" and in section 2.2, "Purpose and Need for Agency Action." This phrase was inadvertently left over from an earlier version of the draft EA. There are no current plans or projected plans to process $\mathrm{Pu}-238$ for any terrestrial missions.

Concern \#2: The EA does not clearly define the current status of all missions for which Pu-238 might be needed.

Response \#2: Table 1-1 has been added to the EA and lists all the missions for which Pu-238 might be needed. Table 1-1 also indicates the current status (as of March 1995) of each of these missions. The status identifies the current status of $\mathrm{Pu}-238$ production for each mission as well as the overall status of those activities needed to support each mission. 
Concern \#3: The EA does not specify which of the missions listed in Table 2-1 are funded or the current status of planning for each mission.

Response \#3: Table 1-1 has been included in the EA to indicate which of the missions has been funded. The table indicates that funding has been approved for $\mathrm{Pu}-238$ processing at SRS to support all NASA's missions; however, the funding for each individual mission is not expected to be approved until the year prior to the scheduled launch dates. A discussion concerning the funding and budget process has been included in section 1.0 of the EA. Table 1-1 also indicates the current status (as of March 1995) of each of these missions. The status identifies the current status of $\mathrm{Pu}-238$ production for each mission as well as the overall status of those activities needed to support each mission.

Concern \#4: The EA should better describe and provide more timely information concerning the inventory of weapons return $\mathrm{Pu}-238$ and its plans for reprocessing.

Response \#4: Section 1.1.2 of the EA has been revised to clearly identify the inventory of weapons return $\mathrm{Pu}-238$, and current plans for reprocessing this material. When the EA was originally transmitted for review and comment (October 1994), DOE had insufficient information on the availability of weapons return $\mathrm{Pu}-238$, and initially determined that weapons return $\mathrm{Pu}-238$ would not be used for NASA missions. Since October 1994; however, DOE received information that approximately 10 kilograms of $\mathrm{Pu}-238$ will be available from weapons returns and is considering using this material if it is suitable for space power systems. This additional 10 kilograms has been added to the total inventory of $\mathrm{Pu}-238$ that is available for processing, bringing the total inventory to 52 kilograms.

\subsection{ERF Comment 2}

The EA should better analyze alternatives to future HB-Line operations. TA-55 at the Los Alamos National Laboratory is not considered a viable alternative because it "could only produce gram quantities of Pu-238." (p. 6) The draft EA does not indicate whether "gram quantities" refers to production of only a few grams over several months or hundreds of grams per month. Moreover, the draft EA does not examine modification of the TA-55 facility in order to increase its throughput. The revised draft EA should include these and other details in a meaningful review of the use of TA-55 for some or all Pu-238 processing.

In evaluating the alternative of purchasing $\mathrm{Pu}-238$ from Russia, the draft EA states: "Even if this $35 \mathrm{~kg}$ is purchased the existing U.S. inventory needs to be processed into a usable product to satisfy current projections of Pu-238 needed to support NASA missions as indicated in Table 2-1." (p. 7) In fact, though, Table 2-1 does not demonstrate that the U.S. inventory would still need to be reprocessed. The table lists a requirement for $26 \mathrm{~kg}$ for Cassini which is already being processed in HB-Line. There are only requirements for another $44 \mathrm{~kg}$ of Pu-238, and apparently these requirements are not for funded missions. At the very least, purchasing $\mathrm{Pu}-238$ from Russia would significantly reduce the amount of future reprocessing needed at SRS. The revised draft EA should provide more details about the prospect of purchasing $\mathrm{Pu}-238$ and more carefully describe the impacts of such action on future processing requirements.

\subsubsection{DOE Response}

This comment raises several concerns involving the failure of the EA to adequately discuss several alternatives to processing Pu-238. A response has been provided for each concern.

Concern \#1: The draft EA does not clearly identify the $\mathrm{Pu}-238$ processing rate of the TA-55 facility and how this rate affects future $\mathrm{Pu}-238$ processing. 
Response \#1: Section 2.2.4 of the EA has been revised to clearly identify that the Savannah River Site is currently the only facility in the U.S. that has the capability to process $\mathrm{Pu}-238$ into a usable form. The TA-55 facility at the Los Alamos National Laboratory currently does not have the capability of processing Pu-238. Therefore, unless facility modifications were made to the TA-55 facility (discussed in concern \#2 below), there would be no affect that TA-55 would have on future $\mathrm{Pu}-238$ processing.

Concern \#2: The draft EA does not examine possible modification of the TA-55 facility in order to increase its processing rate and how modification of this facility could affect future $\mathrm{Pu}-238$ processing.

Response \#2: Section 2.2.4 of the EA has been revised to clearly identify the $\mathrm{Pu}-238$ production rate that would be possible at the TA-55 facility at the Los Alamos National Laboratory. New equipment and facility modifications, followed by extensive testing and demonstration, would be required to begin processing $\mathrm{Pu}-238$ at $\mathrm{TA}-55$. The new processing capability would be limited to 100 to 300 grams of $\mathrm{Pu}-238$ per month. This represents the maximum potential capacity for processing Pu-238 at the TA-55 facility. (Note: For reference, HB-Line's capacity is 2000 to 4000 grams of Pu-238 per month.) Although modifying the TA-55 facility is an alternate method for supplying $\mathrm{Pu}-238$ to NASA, there is no reason to consider that the environmental impacts of processing Pu-238 at TA-55 would be significantly different than processing Pu-238 at SRS. Since the environmental impacts would not be significantly reduced, and since additional funding would be required to modify the facility, perform testing, and conduct startup reviews, modifying the TA-55 facility is not considered an to be a reasonable alternative for processing $\mathrm{Pu}-238$ to support NASA missions.

Section 2.2.4 of the EA has also been revised to discuss that modifying the TA-55 facility would not have a significant affect on future $\mathrm{Pu}-238$ processing, and is not considered to be a reasonable alternative for supporting $\mathrm{Pu}-238$ requirements for NASA missions. The next mission for which $\mathrm{Pu}-238$ must be supplied is the Mars Environmental Survey (MESUR) launch in the year 2000. This mission requires $10 \mathrm{~kg}$ of material. Due to the steps involved in transforming the Pu-238 into assembled and fully qualified RTGs, the $10 \mathrm{kgs}$ of Pu-238 must be processed by approximately 1998. Assuming that Pu-238 processing at the TA-55 facility to support MESUR could not begin until 1996 (time would be required to modify the facility, perform testing, and perform the necessary startup approvals), there would be approximately 24 months before the Pu- 238 would have to be delivered to begin RTG fabrication. At an maximum production rate of 300 grams per month, TA-55 would only be able to supply 7.2 kilograms by $1998,2.8$ kilograms below the requirement. This deficit would need to be supplied by alternate means, such as additional purchases from Russia or other foreign nations (see concern \# 4), or continued operation of the HB-Line facility at SRS.

Purchasing the additional material from Russia to make up the $2.8 \mathrm{~kg}$ deficit is not considered to be a reasonable alternative (as noted in the response to concern \#4) since the cost of purchasing $\mathrm{Pu}$ 238 exceeds the cost of processing the material at the HB-Line facility. Even if there were no cost savings, there is no reason to consider that the environmental impacts of processing $\mathrm{Pu}-238$ in Russia would be significantly different than processing Pu-238 in the U.S.

The $2.8 \mathrm{~kg}$ deficit could also be made up by operating the HB-Line facility. Operating both the TA-55 facility and the HB-Line facility is not considered to be a reasonable alternative. The HBLine facility, by itself, can support the NASA missions. Therefore, there is no reason to supply additional funding to TA-55 to perform facility modifications, testing and startup reviews to obtain the capability to process $\mathrm{Pu}-238$, when $\mathrm{Pu}-238$ processing capabilities already exist within the $\mathrm{HB}$ Line facility. Even if there were no costs associated with providing TA-55 the capability to process $\mathrm{Pu}-238$, there is no reason to consider that the environmental impacts of processing Pu-238 at the TA-55 facility would be significantly different than processing $\mathrm{Pu}-238$ at the HB-Line facility. 
Based upon the above discussions, a modified TA-55 facility, by itself, would not be capable of supplying the necessary quantities of $\mathrm{Pu}-238$ to support NASA missions. Therefore, DOE has concluded that the proposed action is to continue to operate and maintain the $\mathrm{Pu}-238$ processing facilities at SRS.

Concern \#3: Table 2-1 does not demonstrate that the U.S. inventory of Pu-238 would still need to be processed into a usable product to support NASA missions even if $35 \mathrm{~kg}$ of $\mathrm{Pu}-238$ is purchased from Russia.

Response \#3: Section 2.2.5 of the EA has been revised to clarify that the entire existing U.S. inventory of Pu-238 does not need to be processed to support the NASA missions. This is independent of whether additional material is purchased from Russia. The EA has also been revised to clarify that purchasing additional materials is not a reasonable alternative for processing $\mathrm{Pu}-238$ at SRS to support NASA missions.

Table 1-1 indicates that a total of $70 \mathrm{kgs}$ of $\mathrm{Pu}-238$ are required to support NASA missions. Subtracting $26 \mathrm{~kg}$. for the Cassini mission (the Pu-238 required to be processed is nearly complete), and subtracting $7.5 \mathrm{~kg}$ for the Pluto Flyby missions (the $\mathrm{Pu}-238$ required for these missions is expected to be provided from an existing spare RTG) results in a total of $36.5 \mathrm{kgs}$ which are needed to support the remaining missions. This is the flight quantity of processed fuel that could be required after Cassini, but it is not the total quantity of $\mathrm{Pu}-238$ required to be processed. In addition to the flight quantity, additional fuel would require processing to account for analytical samples, product characterization, safety testing, spare hardware, and out of specification products. As discussed in section 1.0 of the EA, these "non-flight" quantities may approach $25 \%$ of the flight quantities. Therefore, it is reasonable to consider that $45.7 \mathrm{~kg}$ of Pu238 would be required to be processed so that $36.5 \mathrm{~kg}$ will be available as the flight quantity.

DOE has an existing contract with Russia to purchase an additional $35 \mathrm{~kg}$. of Pu-238. A second purchase of Pu-238 from Russia is anticipated to occur during early Fiscal Year 1995. This purchase will consist of approximately $4 \mathrm{~kg}$ of material which will not require processing prior to fuel pellet fabrication. This reduces the quantity of Pu-238 to support NASA missions from 36.5 $\mathrm{kg}$. to $32.5 \mathrm{~kg}$. It also reduces the quantity of Pu-238 that is available to be purchased from Russia from $35 \mathrm{~kg}$. to $31 \mathrm{~kg}$. Therefore, it "appears" that if the remaining $31 \mathrm{~kg}$. of Pu-238 is purchased form Russia, only a $1.5 \mathrm{~kg}$. deficit would result. This would "imply" that only a small quantity of the U.S. inventory of Pu-238 would require processing to meet NASA mission needs.

However, DOE only has $\$ 9.1$ million allocated towards the Pu-238 program through Fiscal Year 1996. Due to budgetary limitations, DOE does not anticipate that additional funds will be available for the Pu-238 program in later years. Therefore, there is only $\$ 9.1$ million available to support the NASA missions. DOE has two options: 1)purchase $\$ 9.1$ million in Pu-238 from Russia under the existing contract; or 2) operate HB-Line at a cost of $\$ 1.1$ million per month and process that quantity of $\mathrm{Pu}-238$ until the $\$ 9.1$ million is depleted.

If DOE purchases $\$ 9.1$ million in $\mathrm{Pu}-238$ from Russia, the U.S. will receive approximately $6.5 \mathrm{~kg}$ of material. This is based upon the cost of $\$ 1,409$ per gram, and does not include the cost increase of $5.5 \%$ per year. The $6.5 \mathrm{~kg}$. purchased can be combined with the $4 \mathrm{~kg}$. of Pu-238 recently approved for purchase for a total of $10.5 \mathrm{~kg}$. This will support the MESUR launch in 2000, but will not support any other NASA missions.

If DOE operates HB-Line, $20 \mathrm{~kg}$. of $\mathrm{Pu}-238$ can be processed for $\$ 9.1$ million. This is based upon processing for 8 months at an average capacity of $2.5 \mathrm{~kg}$ per month. At a operating cost of $\$ 1.1$ million per month, this would cost $\$ 8.8$ million. The remaining $\$ 0.3$ million would be used to flush out the lines. The $20 \mathrm{~kg}$. processed through $\mathrm{HB}-\mathrm{Line}$ can be combined with the $4 \mathrm{~kg}$. 
recently approved for purchase from Russia, for a total of $24 \mathrm{~kg}$. This would not support all of the NASA missions; however, it supports more missions than purchasing the material from foreign nations.

In addition to the cost of the $\mathrm{Pu}-238$, there is no reason to consider that the environmental impacts of processing $\mathrm{Pu}-238$ in Russia would be significantly different than processing $\mathrm{Pu}-238$ in the U.S.

With the budget available, DOE cannot support all of the NASA missions. There is enough material in the U.S. inventory to support NASA's needs; however, the funds are not available to support processing all the material that is required. Based upon a cost/benefit analysis as well as evaluating the environmental impacts of purchasing versus processing, DOE has concluded that the proposed action is to continue to operate and maintain the Pu-238 processing facilities at SRS.

Concern \#4: The draft EA should provide more details about the prospects of purchasing Pu-238 and describe the impacts that this action would have on future $\mathrm{Pu}-238$ processing.

Response \#4: Sections 1.1.1 and 2.2.5 of the EA has been revised to provide more details concerning purchasing additional material from foreign nations.

A second purchase of $\mathrm{Pu}-238$ from Russia has been approved which is anticipated to occur during early Fiscal year 1995. This purchase will consist of approximately $4 \mathrm{~kg}$ of material which will not require processing prior to fuel pellet fabrication. This would reduce the flight quantity of $\mathrm{Pu}-238$ required to support post Cassini NASA missions from $36.5 \mathrm{~kg}$. to $32.5 \mathrm{~kg}$ (see response to concern \#3). Additional purchases from Russia under this existing contract, or from other foreign nations, are not anticipated due to budget limitations. Therefore, $32.5 \mathrm{~kg}$ of flight quantity Pu-238 from the existing U.S. inventory would require processing to support the post Cassini NASA missions.

Discussion with Great Britain and France have concluded that kilogram quantities of Pu-238 would not be available until sometime after 1999, after significant investment in new facilities have been completed. Receiving material in the year 1999 would not support the proposed launch of MESUR in the year 2000 due to the long lead time necessary to fabricate the RTGs (see response to concern \#2)

Based upon the above discussions, DOE has concluded that the proposed action to best support the post Cassini NASA missions is to continue to operate and maintain the $\mathrm{Pu}-238$ processing facilities at SRS.

\subsection{ERF Commẹnt \#3}

A substantial concern raised about the $1991 \mathrm{EA}$ was its incomplete consideration of waste management impacts. Unfortunately, the current draft is even less adequate in this regard. The draft EA merely references two ongoing Environmental Impact Statements (EIS), with the Waste Management EIS apparently being most considerate of future HB-Line operations. (pp. 3, 12, \& 16) The Waste Management EIS, however, won't be complete for several months. Consequently, a decision soon on the EA would not be based on any meaningful review of waste management impacts associated with HB-Line operations. To correct this problem, the revised draft EA should thoroughly describe the waste streams which would be generated by HB-Line operations, how the waste will be handled, and potential impacts.

Despite the incomplete discussion in the draft EA, the proposed Finding of No Significant Impact presents the conclusion that, "Waste generated as a result of the proposed action would be a small fraction of the waste being managed at the SRS and would require no new waste management 
facilities or process." (p. 4) If this is DOE's conclusion, then the revised draft EA must provide supporting evidence.

\subsubsection{DOE Response}

Section 4.3 of the EA has been revised to clearly describe the waste streams which are generated by HB-Line operations, the method that the waste is handled, and the potential impacts of the waste. This discussion supports the conclusion provided in the FONSI that waste generated as a result of the proposed action would be a small fraction of the waste being managed at the SRS and would require no new waste management facilities or process.

Based upon a review of the waste management impacts, DOE has determined that the proposed action does not significantly affect the quality of the human environment within the meaning of NEPA. Therefore, DOE has concluded that the preparation of an Environmental Impact Statement is not required, and is proposing to issue a Finding of No Significant Impact.

\subsection{ERF Comment \#4}

The draft EA does not calculate doses from accidents to involved facility workers. The rationale provided is that the estimates rely on many assumptions and that in most cases "DOE believes that accident response procedures and engineered safety systems would limit worker doses to the range shown for co-located workers." (p. 18) The final EA should provide risk information for workers involved in accidents, or at the very least offer a clear explanation of why such information is not included. This information should not be based solely on historical practices, but rather it should reflect current expectations about the operation of DOE nuclear facilities.

\subsubsection{DOE Response}

Table 5-5 has been included in the final EA to provide risk information for workers involved in potential accidents. The request to include this information in the EA is consistent with the guidance presented in "Recommendation for the Preparation of Environmental Assessments and Environmental Impact Statements," U.S. Department of Energy, Office of NEPA Oversight, May 1993. Specifically, section 6.2 states, "Aim to provide estimates of potential health effects from chemical or radiological exposure for three subsets of populations and maximally exposed individuals in those populations: (1) workers that would be involved in the proposed action,. (2) noninvolved workers (workers that would be on the site of the proposed action but not involved in the action), and (3) members of the general public.

Historicaliy, DOE provided estimates of potential health effect to noninvolved workers (e.g. colocated workers) and members of the general public; however, DOE did not specifically identify the health effects to the actual worker. It was believed that accident response procedures and engineered safety systems would limit worker doses to the range determined for co-located workers. In addition, any uncertainties associated with modeling of accident at small distances (e.g. within the building) would be extremely large, and the consequences resulting from such models would tend to vary by orders of magnitude, depending on the selection of assumptions.

In order to more closely follow the suggestion to "aim to provide estimates of potential health effects to workers that would be involved in the proposed action," a qualitative analysis was performed to evaluate the hazards to the facility workers. The results of this analysis are presented in section 5 of the EA. The results are summarized from a Preliminary Hazards Analysis (PHA) which was conducted for the facility following the guidelines presented in DOE Standards DOESTD-3011-94, "Guidance for Preparation of DOE 5480.22 (TSR) and DOE 5480.23 (SAR) Implementation Plans." Based upon the information obtained in the PHA, a qualitative accident 
analysis was performed to evaluate the hazards, the cause of each hazard, the frequency, the consequences, and the preventive or mitigative systems that are in place to protect the workers.

Based upon the review of the hazards to the facility workers, DOE has determined that the proposed action does not significantly affect the quality of the human environment within the meaning of NEPA. Therefore, DOE has concluded that the preparation of an Environmental Impact Statement is not required, and is proposing to issue a Finding of No Significant Impact.

\subsection{ERF Comment \#5}

The revised draft EA should describe recent operating experience of the HB-Line and explain the risks associated with the operations.

\subsubsection{DOE Response}

Section 1.1.3 of the EA provides an adequate discussion of operations from January 1991 to the present. This subsection includes a brief discussion on the June $1994 \mathrm{H}$-Canyon Water Hammer incident which caused the Frame Waste Recovery process to shut down. The facility recovered form the incident and operations have resumed. DOE considers that listing every occurrence associated with HB-Line is outside the scope of the EA. A description of all occurrences associated with HB-Line, as well as summaries of production activities, are provided to you through monthly status reports.

The risks associated with operations are discussed in sections 5.1 and 5.3 of the EA. Section 5.1 .5 concludes that under normal operations, workers engaged in the operations of HB-Line and Frame Waste Recovery would not be expected to incur any harmful health effects from radiation exposures they receive. Section 5.3.1 quantifies the risks and estimates that there would be 0.04 Latent Cancer Fatalities per years during normal operations. DOE considers that this does not present a significant affect on the quality of the human environment within the meaning of NEPA.

\subsection{ERF Comment \#6}

There are several other specific concerns addressed in Court documents which are not adequately discussed in the draft EA. For example, we raised detailed concerns about hazards associated with $\mathrm{Pu}-238$, on-site and off-site radiological impacts, several specific concerns about accidents, and safety issues such as fire protection, procedures and training, and Order compliance. Each of these should be covered in the revised draft EA.

\subsubsection{DOE Response}

The specific concerns raised in comment \#6 were identified in court documents (Motion for Summary Judgment, Civil Action No. 3:93-0001-19, transmitted to the Secretary of Energy on June 29, 1993) and are identified below. For each concern listed, a response is provided; however, the EA may not have been revised as requested. DOE considers that the scope of several of the concerns (e.g. DOE Order compliance) are outside the scope of the EA. In these instances, the response provides the necessary details to resolve the concern.

Concern \#1: Hazards Associated with Plutonium-238 - The comments raised in court documents suggest that the EA does not address the potential health effects associated with plutonium- 238 .

Response \#1: The hazards associated with $\mathrm{Pu}-238$ are described in section 5 of the EA. The EA addresses the hazards associated $\mathrm{Pu}-238$ that are present during normal operations and credible accidents, and describes the effects these hazards have on the workers, the public, and the environment. Specifically, section 5.3 of the EA discusses that the major impact from operation of 
HB-Line under both normal and accident conditions is exposure to radiation. The EA identifies in Table 5-14 that during normal operations there is a potential for 0.04 latent cancer fatalities (LCFs) due to radiation exposure. The greatest number of LCFs is expected during an earthquake which is expected to result in 2 LCFs on-site and 5 LCFs off-site. Numerous references are cited from which additional details concerning detailed analyses and excess cancer mortality conversion factors for on-site and off-site exposure to $\mathrm{Pu}-238$ can be obtained. This will enable the reviewer to independently verify the information contained in the EA.

Based upon a review of the hazards of Pu-238 which are summarized in the EA, DOE has determined that the proposed action does not significantly affect the quality of the human environment within the meaning of NEPA. Therefore, DOE has concluded that the preparation of an Environmental Impact Statement is not required, and is proposing to issue a Finding of No Significant Impact.

Concern \#2: On-site and off-site radiological impacts - The comments raised in court documents suggest that the EA offers no support that there are no significant radiological impacts from processing $\mathrm{Pu}-238$.

Response \#2: The EA adequately describes the on-site and off-site radiological impacts in section 5. Specifically, the radiological impacts are identified for the on-site (co-located) worker, the onsite (facility) worker, the on-site population, the maximum off-site individual, and the off-site population. Similar to the concern raised about the hazards associated with $\mathrm{Pu}-238$ (discussed above), the EA discusses that the major impact from operation of HB-Line under both normal and accident conditions is exposure to radiation. Numerous references are cited from which additional details concerning accident analysis and dispersion models which were used to determine the radiological impacts can be obtained. This will enable the reviewer to independently verify the information contained in the EA. New qualitative analysis has been performed to identify the risks to on-site facility workers and calculations were recently updated based upon new meteorological and population databases.

Based upon the on-site and off-site radiological impacts summarized in the EA, DOE has determined that the proposed action does not significantly affect the quality of the human environment within the meaning of NEPA. Therefore, DOE has concluded that the preparation of an Environmental Impact Statement is not required, and is proposing to issue a Finding of No Significant Impact.

Concern \#3: Accidents - The comments raised in court documents suggest that the EA does not properly summarize data from various safety analysis documents and that the EA does not identify those accidents which result in the highest doses and risks.

Response \#3: The EA adequately describes in section 5.2 the potential credible accidents which could occur within the HB-Line facility, and summarizes the accident scenarios which result in the highest doses (propagated fire) and highest risks (low energetic event). Calculations were recently updated to provide the co-located worker, on-site population, and off-site population doses based upon the new meteorological and population databases. The updated analysis shows that accident consequences remain within the authorization basis outlined in the Safety Analysis Report and Justification for Continued Operation. In addition, the results of a qualitative analysis have been summarized in the EA which identifies the consequences to facility workers from numerous hazards within the facilities.

The current draft EA contains information from the Safety Analysis Report and the Justification for Continued Operation, as well as several new, updated analyses that have been conducted. Numerous references are cited in the EA from which additional details concerning accident 
scenarios and new analyses can be obtained. This will enable the reviewer to independently verify the information contained in the EA.

Concern \#4: Fire Protection - The comments raised in court documents suggest that the EA failed to recognize deficiencies with the HB-Line fire protection systems.

Response \#4: The July $1991 \mathrm{EA}$ and the current draft EA are not required to make direct mention of risks associated with the fire protection systems. The risks associated with these systems are discussed in detail in section 3.6.2 of the Justification for Continued Operation which is referenced in the EA. The analysis presented in the JCO identifies the risks and consequences resulting from a propagated fire. This analysis assumes failure of the existing fire detection, Halon fire suppression, and HEPA filtration systems within the facility. These assumptions therefore eliminate any issues associated with the deficiencies and/or risks of these fire protection systems. The only safety system for which credit is taken is the passive sand filter. These assumptions result in a very conservative analysis, the conclusions of which indicate that a propagated fire is the accident resulting in the highest dose to any receptor. Although the propagated fire is the accident with the highest doses, the doses are acceptable. (Note: The accident which results in the highest risk is a low energetic event, and is discussed in the response to the concern involving "Procedures and Training".)

Since the JCO accounted for failure of the existing fire detection, Halon fire suppression, and HEPA filtration systems, DOE considers that the analysis discussed in the JCO is adequate in that it accounts for any deficiencies and/or risks associated with the fire protection systems. Since the potential doses from a propagated fire are acceptable and do not significantly affect the quality of the human environment within the meaning of NEPA, DOE considers that the EA is adequate.

Concern \#5: Procedures and Training - The comments raised in court documents suggest that inadequacies in procedures and training compromise the assumptions in the accident analyses, thus compromising the results summarized in the EA.

Response \#5: The EA identifies that the maximum risk from operating HB-Line is due to a low energetic event. The assumptions for a low energetic event documented in the Safety Analysis Report conservatively take no credit for operator response, the operator being properly trained, or the facility having procedures in place to mitigate an abnormal situation. These assumptions therefore eliminate any issues associated with inadequacies in the procedures and training programs. These assumptions result in a very conservative analysis, the conclusions of which indicate that a low energetic event is the accident resulting in the highest risk. Although the low energetic event is the accident with the highest risk, the risk is acceptable. (Note: The accident which results in the highest dose is a propagated fire, and is discussed in the response to the concern involving "Fire Protection".)

Since the SAR accounted for failure of an operator to respond to an abnormal situation, failure to properly train personnel, and failure to have procedures in place, DOE considers that analysis discussed in the SAR is adequate in that it accounts for any inadequacies in procedures and training. Since the potential risk from a low energetic event is acceptable and do not significantly affect the quality of the human environment within the meaning of NEPA, DOE considers that the $\mathrm{EA}$ is adequate.

Concern \#6: Order Compliance - The comments raised in court documents suggest that lack of compliance with DOE Orders potentially invalidates assumptions upon which the EA is based.

Response \#6: Although DOE considers that the general issue of DOE Order compliance is not relevant to the adequacy/validity of the EA (with the exception of DOE Order 5440.1C, "National Environmental Policy Act Compliance Program"), documentation of compliance with DOE Orders 
is complete as documented in the Justification for Continued Operation. The HB-Line facility has performed compliance assessment for all DOE Orders important to the health and safety of the workers, the public, and the environment. All non-compliances have been identified, along with compensatory and corrective actions, and documented. The non-compliances did not invalidate any assumptions upon which the EA is based; thus DOE considers that the EA is adequate.

\subsection{COMMENTS TRANSMITTED TO DOE FROM MR. W. LEE POE, JR., DECEMBER 9, 1994}

\section{1 - Mr. Poe's Comment 1}

The principal thrust of this EA is to process scrap materials and produce specification grade plutonium oxide for future NASA missions. From the information given in the EA and from comments made at the public meeting on December 6, the available Pu-238 at SRS plus that shipped to SRS from Mound and Los Alamos exceed demand by 30 to $35 \mathrm{~kg}$. In addition the EA considers a possible additional $35 \mathrm{Kg}$ from future Russian stocks. Section 3.1 and other parts of the EA, as appropriate, should be expanded to include discussion of the DOE plans for safe storage of this excess Pu-238. This should include expectations on types of materials that will be stored, how stored and in what from, their safety in long-term storage, schedules for achieving safe storage, etc. It is recognized that the recent Plutonium ES\&H Vulnerability Assessment identified several $\mathrm{HB}$-Line vulnerabilities associated with $\mathrm{Pu}-238$. Bringing the Mound, Los Alamos scrap materials and the Russian Pu-238 to SRS, as authorized under this EA, complicate this long-term issue at SRS and as a result, it should be addressed in this NEPA document.

\subsubsection{DOE Response}

Section 1.0 and Table $1-1$ of the EA have been extensively revised to more fully explain DOE's obligation to provide $\mathrm{Pu}-238$ for NASA missions and describe the existing $\mathrm{Pu}-238$ inventory (including the potential for further purchases from Russia). In addition, DOE has provided a detailed discussion of the issue of need for specification $\mathrm{Pu}-238$ in sections 1.1.1 and 1.2.1 of this Appendix.

Continued safe management and storage of nuclear materials at the Savannah River Site (including $\mathrm{Pu}-238$ ) is evaluated in the draft Interim Management of Nuclear Materials EIS (DOE/EIS-0220D), issued in March 1995.

\subsection{Mr. Poe's Comment 2}

Since this EA excludes some Pu-238 materials (e.g., weapons returns) what NEPA document covers recovery processing, storage, etc. of these excluded materials.

\subsubsection{DOE Response}

The proposed action has been revised to include processing of about $10 \mathrm{~kg}$ of weapons returns $\mathrm{Pu}-$ 238 (see section 1.1.2). There are currently no plans to process additional weapons returns $\mathrm{Pu}$ 238. Recovery and storage of nuclear materials from dissassembled weapons is currently being evaluated in the Pantex Plant Site-wide EIS and other ongoing NEPA reviews, including the EA for storage of enriched uranium at Oak Ridge and the EIS on storage and disposition of weaponsusable fissile materials.

\subsection{Mr. Poe's Comment 3}

The alternative discussion in this EA seem extremely terse. Section 3.2 identifies five alternatives to the proposed action. There are 1) No Action, 2) Alternative Processing Facility, 3) Alternative 
Vault Storage Facility, 4) Processing at the National Laboratories, and 5) Purchase of Pu-238 from Foreign Nations. Each of these alternatives were written off with a few sentences of prose. None of the alternatives were analyzed to show environmental effects.

\subsubsection{DOE Response}

DOE has revised the discussion of alternative in the EA and added a sixth alternative, Alternative Packaging and Storage of $\mathrm{Pu}-238$, as described in section 2.2.6. Additional explanation of the alternatives is given in the response to ERF comment 2, section 1.2.1 in Appendix A.

DOE guidance on discussion of alternatives in environmental assessments indicates that “... EAs often can focus the quantitative analysis on the proposed action; that is, discussions of alternatives in EAs generally can be qualitative." This EA presents a broad range of reasonable alternatives. If, on the basis of the analysis of the proposed action in this EA, the Department determined that potentially significant impacts to the human environment could result from implementation of the proposed action, the Department would prepare an EIS which would quantitatively evaluate the impacts of the alternatives.

\subsection{Mr. Poe's Comment 4}

Do the environmental effects of the proposed action, given in Section 6.0, properly reflect the post Cassini effects of $\mathrm{Pu}-238$ processing at SRS? The environmental effects shown in Section 6.1 are expressed as either impact/year or impact/g or $\mathrm{Kg} \mathrm{Pu-238.} \mathrm{No} \mathrm{specific} \mathrm{operation} \mathrm{period} \mathrm{was}$ identified nor quantity of Pu-238 processed. Table 6-1 does, provide the expected emissions per gram $\mathrm{Pu}-238$ and the total emissions. This allows me to figure out the $\mathrm{Kg}$ of Pu-238 considered. It turns out to be about $43 \mathrm{Kg} \mathrm{Pu}-238$ of the amount of Pu-238 in the NASA demand. This doesn't seem to cover the full amount of Pu-238 planned to be processed. Please show information that allows total environmental effects from normal operations to be determined.

\subsubsection{DOE Response}

The information given in the section on Environmental Consequences (section 5.0) reflects the impacts of processing the currently available inventory of $\mathrm{Pu}-238$. This inventory, as indicated in Table $5-1$, is approximately $52 \mathrm{~kg}$. Most impacts of normal operations are presented in section 5.0 on an annual or per unit Pu-238 basis. DOE chose this presentation because the quantity of $\mathrm{Pu}-$ 238 that would be processed after completion of the Cassini mission is not precisely known. Similarly, the exact period of time required to process the inventory can be estimated (based on the current average processing rate of $2.5 \mathrm{~kg}$ per month, approximately 21 months would be required to process the $52 \mathrm{~kg}$ inventory) but cannot be known exactly.

\subsection{COMMENTS RECEIVED AT THE PUBLIC MEETING HELD IN NORTH AUGUSTA, SOUTH CAROLINA, DECEMBER 6, 1994}

\subsection{Comment by Mr. Bob Overman}

You are wasting the taxpayers money to write an EIS every time a product is used for a different purpose. The lines have been running but since the purpose has changed, you have to do an EIS. But the process hasn't changed. Plutonium is plutonium. The hazards are the same no matter how you're going to use it. I support the preferred alternative. I vote in favor of keeping going (continued operation).

\subsubsection{DOE Response}


DOE agrees that the hazards involved in operating the HB-Line to support post-Cassini missions are the same as those involved in current and previous operations. The preparation of this EA is the result of the settlement of a suit filed against the Department by the Energy Research Foundation of Columbia, South Carolina, as described in section 1.1.3. of the EA.

\subsection{Comment by Mr. Lee Poe}

You ought to include information on scrap and residue processing in the EA.

\subsubsection{DOE Response}

See the DOE response to Mr. Poe's similar question in Appendix A, section 2.2.1.

\subsection{COMMENTS RECEIVED AT THE PUBLIC MEETING HELD IN SAVANNAH, GEORGIA, DECEMBER 8, 1994}

\subsection{Comment by Mr. George Minot}

Publish the information such as waste generation, in terms the public can understand.

\subsubsection{DOE Response}

Waste generation from HB-Line operations is given in section 5.1.6 of the EA. Table 5-4 describes the volume of waste, by waste type, generated by HB-Line operations, and shows the total quantity of those wastes that exist at the Savannah River Site. Waste generation and waste management at the Savannah River Site is a complex issue, and is the subject of an environmental impact statement publish in draft in January 1995 (Savannah River Site Waste Management Draft Environmental Impact Statement, DOE/EIS-0217D).

\subsection{Comment by Mr. George Minot}

My concern is that I haven't read or heard in this meeting any real good reason to keep the process running. The public needs more substantiation or commitment from NASA and the budget process. I believe the HB-Line should be shut down or placed in a standby mode.

\subsubsection{DOE Response}

Section 1.0 and Table 1-1 of the EA have been extensively revised to more fully explain DOE's obligation to provide $\mathrm{Pu}-238$ for NASA missions, describe the existing Pu-238 inventory, and explain the Federal budget process. In addition, DOE has provided a detailed discussion of the issue of need for specification Pu-238 in sections 1.1.1 and 1.2.1 of this Appendix.

\subsection{Comment by The Reverend Susan S. Dulany}

I do not want spent nuclear fuel rods coming to Savannah, Georgia. I do not want it to get any worse. I understand that SRS is one of the most dangerous sites in the United States.

\subsubsection{DOE Response}

The proposed action addressed in this environmental assessment does not involve shipment of spent nuclear fuel to the United States. The Department is preparing an environmental Impact Statement on a Proposed Nuclear Weapons Nonproliferation Policy Concerning Foreign Research Reactor Spent Nuclear Fuel. The Draft EIS will be available in April 1995 and a public meeting will be held in Savannah, Georgia in May, 1995. This proposal could involve shipment of spent 
nuclear fuel to the Savannah River Site. Savannah is one of 10 potential ports of entry for these shipments.

\subsection{COMMENTS AND QUESTIONS RECEIVED AT THE WORKSHOP HELD IN NORTH AUGUSTA, SOUTH CAROLINA, JANUARY 18, 1994}

\subsection{Question}

Is there an H-Canyon and HB-Line exhaust system emergency back-up? If not, the existing exhaust stack could shut down the H-Canyon and HB-Line process when the stack liner collapses and blocks the exhausted air.

\subsubsection{DOE Response}

The H-Canyon and HB-Line exhaust systems have multiple exhaust fans supplied by multiple power sources. However, the air exhausted from the H-Canyon and the HB-Line facilities flows through only one stack. There is not an alternate flow path. A detailed safety review study of the impact from the exhaust stack liner collapsing was evaluated, and concluded that the exhaust airflow could be restored within 48 hours. This was determined to be an acceptable amount of time to restore a ventilation flow path. The risk analysis of this event showed that static conditions and typical air reversals would have negligible releases of radioactive materials.

\subsection{Question}

Does the negotiated settlement with ERF include/affect any SRS facilities besides HB-Line? If so, what are they and what are the provisions of the settlement?

\subsubsection{DOE Response}

The negotiated settlement between the Energy Research Foundation (ERF) and the Department of Energy (DOE) only affects the HB-Line facility at the Savannah River Site. The provisions of the settlements are described below.

1. DOE will prepare an Environmental Assessment (EA) that will address the National Environmental Policy Act (NEPA) related issues raised by the plaintiffs in their motion for partial summary judgment concerning the reprocessing of Plutonium (Pu)-238 in HB-Line Phases I and III, including the impacts of reprocessing $\mathrm{Pu}-238$ purchased from Russia and the remaining U.S. inventory, and the need for future $\mathrm{Pu}-238$ reprocessing at SRS.

2. DOE is reviewing its classification policies with a view to decrease the amount of information that is classified and, consistent with that, DOE will review the classified information that is relied on by the EA and will attempt to declassify all or as much of the information as possible, but will prepare a classified appendix if necessary that would include, if appropriate, the classified inventory of $\mathrm{Pu}-238$, any proposed classified uses of $\mathrm{Pu}-238$ and related information.

3. DOE will issue a draft EA and, if appropriate, a proposed Finding of No Significant Impact (FONSI), will solicit public comments, and will consider and respond to all public comments received in issuing the final EA, and, if appropriate, the FONSI or other appropriate final agency action. 
4. Prior to completion of this new NEPA process, DOE will continue operating HB-Line Phase I and III only to reprocess that quantity of $\mathrm{Pu}-238$ needed to support the National Aeronautics and Space Administration's Cassini mission.

5. DOE will provide ERF with a monthly update on the status of progress on the EA and efforts to fulfill Cassini requirements.

6. The monthly updates described above will cease upon completion of the NEPA process on the EA or upon completion of reprocessing Pu-238 in support of the Cassini mission, whichever is later.

7. This Stipulation in no way limits the rights of plaintiffs to challenge the adequacy of the EA to be prepared pursuant to this Stipulation.

\subsection{COMMENTS AND QUESTIONS RECEIVED AT THE WORKSHOP HELD IN SAVANNAH, GEORGIA, JANUARY 20, 1994}

\subsection{Question}

If the Pu-238 is purchased from Russia or any other overseas country, how will it be shipped to SRS?

\subsubsection{DOE Response}

The Russian material is contained in welded, stainless steel cans which are placed in a "Mound 1 Kilowatt Thermal (KW) Package." The Mound 1KW Packages are provided to Russia by the United States. The Mound 1KW Packages have been evaluated analytically and tested to determine its compliance with the applicable regulations for certification.

The Mound 1KW Packages are then placed inside International Shipping Organization (ISO) containers which are locked and sealed with tamper indicating devices. The ISO containers are transported by rail to St. Petersburg, a Russian seaport. The ISO containers are then loaded by crane onto a Russian cargo vessel. The material then proceeds by ship, non-stop, to a designated port.

Upon arrival in the designated port, the tamper indicating devices on the ISO containers are inspected, and an exterior radiation survey is conducted. The ISO containers are then off loaded from the Russian cargo vessel by crane onto the dock. The ISO containers are transferred to a designated handling area where the Mound 1KW Packages are removed. Following removal from the ISO containers, the Mound 1KW Packages are transferred by forklift onto Safe Secure Trailers (SSTs). The SSTs are then transported by truck over interstate highways to SRS by the Department of Energy Albuquerque Operations Office's Transportation Safeguards Division.

\subsection{Question}

Why, with all the past, present,. and future potential for contamination, do we continue to manufacture or reprocess the elements, other than national security? Is the Cassini worth the risk?

\subsubsection{DOE Response}

The current and future mission of HB-Line Phases I and III is focused on processing plutonium $(\mathrm{Pu})-238$ to be used in power sources for space exploration missions by the National Aeronautics and Space Administration (NASA). 
The safety of using the $\mathrm{Pu}-238$ fueled power sources, called Radioisotope Thermoelectric Generators (RTGs), on any particular mission is carefully analyzed, and then reviewed by an Interagency Nuclear Safety Review Panel. This panel reports its results to the White House. The decision to launch a satellite with nuclear materials aboard is made at the White House, either by the Office of Science and Technology Policy, or by the President. The decision is made on a riskbenefit basis. The existing Environmental Assessment (EA) for HB-Line describes in detail the risks associated with processing $\mathrm{Pu}-238$ in the $\mathrm{HB}$-Line facility. The EA currently being prepared for processing $\mathrm{Pu}-238$ for post-Cassini space missions, will also describe the risk of processing $\mathrm{Pu}-238$.

The RTGs are the only power systems that can meet the needs of deep space planetary missions. These missions are too far from the Sun for solar panels to be effective, and the missions take too long to use batteries. . RTGs are referred to as an "enabling technology" for deep space missions. The Voyager, Galileo, and Ulysses spacecrafts are examples of NASA missions that have used RTGs to power instruments on the spacecrafts. The Department of Energy has developed and provided radioisotopes power systems for space and terrestrial missions for the past 30 years. The scientific and technical knowledge gained from these space missions are vastly expanding our knowledge of the universe.

Cassini, the first spacecraft to orbit Saturn and its moons, will conduct detailed studies of Saturn's atmosphere, rings, magnetosphere, and moons. Information gathered from these studies may lead to a better understanding of the evolution of the Earth's atmosphere.

\subsection{Question}

There is no treatment for exposure, once exposed, it is on a molecular level and you are a timebomb. Are there any special medical personnel to deal with the individual, or God forbid, mass contamination?

\subsubsection{DOE Response}

Exposure levels at the Savannah River Site are maintained at or below the established Federal and Department of Energy Savannah River Operations Office (DOE-SR) guidelines. For example the Federal occupational exposure limit is $5 \mathrm{rem} / \mathrm{year}$, while the DOE-SR occupational exposure limit is $2 \mathrm{rem} / \mathrm{year}$. Based on analysis, this level of exposure on an annual basis would not result in any harmful effects.

The issue of a "time-bomb" would only apply in an acute case (a large dose over a very short period of time) of exposure which SRS has never experienced. Medical and Radiological Control Organization personnel are trained to handle contamination cases, whether individual or in mass. The facilities are also equipped to handle personnel decontamination.

There are special medical techniques available, such as chelation and iodine pills, that help reduce the body's absorption of radionuclides. The Eisenhower Medical Center at Fort Gordon in Augusta, Georgia has special facilities to deal with contaminated and injured people. If the mass contamination was external contamination, it would be handled onsite. However, if the accident lead to large numbers of people with internal contamination, it would be handled by the Eisenhower Medical Center.

\subsection{Question}

What do we as a community and a public have to gain directly and what is its ratio to the risk?

\subsubsection{DOE Response}


The benefit that the community and public receives from space exploration is in the advancement in the understanding of our universe, while at the same time, providing economic support to the communities.

The current and future mission of HB-Line Phases I and III are focused on processing Plutonium (Pu)-238 to be used in power sources for space exploration missions by the National Aeronautics and Space Administration (NASA).

The safety of using the $\mathrm{Pu}-238$ fueled power sources, called Radioisotope Thermoelectric Generators (RTGs), on any particular mission is carefully analyzed, and then reviewed by an Interagency Nuclear Safety Review Panel. This panel reports its results to the White House. The decision to launch a satellite with nuclear materials aboard is made at the White House, either by the Office of Science and Technology Policy, or by the President. The decision is made on a riskbenefit basis. The existing Environmental Assessment (EA) for HB-Line describes in detail the risks associated with processing Pu-238 in the HB-Line facility. The EA currently being prepared for processing $\mathrm{Pu}-238$ for post-Cassini space missions, will also describe the risk of processing $\mathrm{Pu}-238$.

The RTGs are the only power systems that can meet the needs of deep space planetary missions. These missions are too far from the Sun for solar panels to be effective, and the missions take too long to use batteries. RTGs are referred to as an "enabling technology" for deep space missions. The Voyager, Galileo, and Ulysses spacecrafts are examples of NASA missions that have used RTGs to power instruments on the spacecrafts. The Department of Energy has developed and provided radioisotopes power systems for space and terrestrial missions for the past 30 years. The scientific and technical knowledge gained from these space missions are vastly expanding our knowledge of the universe.

Cassini, the first spacecraft to orbit Saturn and its moons, will conduct detailed studies of Saturn's atmosphere, rings, magnetosphere, and moons. Information gathered from these studies may lead to a better understanding of the evolution of the Earth's atmosphere.

\subsection{Question}

With NASA cutbacks also forthcoming, will the Cassini mission be at all jeopardized?

\subsubsection{DOE Response}

NASA's fiscal year 1995 budget request of $\$ 14.5$ billions contains full funding for the Cassini mission, and NASA remains confident that its budget request will be supported by Congress. If the full amount requested is provided, the Cassini mission will not be jeopardized. If however, the full amount is not provided, a careful decision will be made as to which programs will not be funded. 